\title{
Energy Storage for DC Fast Chargers
}

\section{Development and}

Demonstration of

Operating Protocols for

20-kWh and 200-kWh

\section{Field Sites}

Russell Newnham ${ }^{a}$

Sally (Xiaolei) Sun ${ }^{a}$

Donald Karner ${ }^{a}$

James Francfort ${ }^{\mathrm{b}}$

March 2013

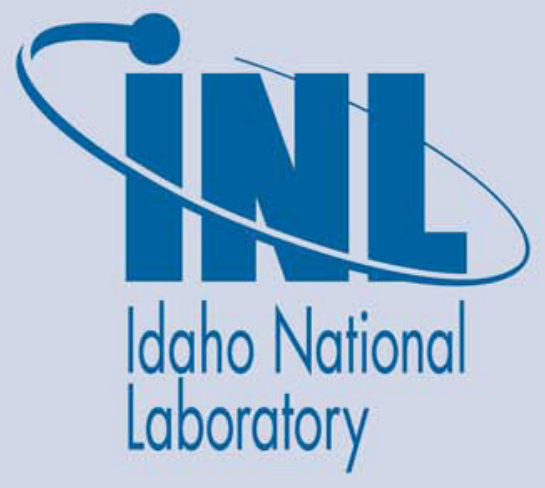

${ }^{a}$ ECOtality North America

${ }^{\mathrm{b}}$ Idaho National Laboratory

The INL is a U.S. Department of Energy National Laboratory operated by Battelle Energy Alliance 


\section{DISCLAIMER}

This information was prepared as an account of work sponsored by an agency of the U.S. Government. Neither the U.S. Government nor any agency thereof, nor any of their employees, makes any warranty, expressed or implied, or assumes any legal liability or responsibility for the accuracy, completeness, or usefulness, of any information, apparatus, product, or process disclosed, or represents that its use would not infringe privately owned rights. References herein to any specific commercial product, process, or service by trade name, trade mark, manufacturer, or otherwise, does not necessarily constitute or imply its endorsement, recommendation, or favoring by the U.S. Government or any agency thereof. The views and opinions of authors expressed herein do not necessarily state or reflect those of the U.S. Government or any agency thereof. 


\title{
Energy Storage for DC Fast Chargers Development and Demonstration of Operating Protocols for 20-kWh and 200-kWh Field Sites
}

\author{
Russell Newnham \\ Sally (Xiaolei) Sun \\ Donald Karner \\ James Francfort
}

March 2013

Idaho National Laboratory Idaho Falls, Idaho 83415

http://www.inl.gov

Prepared for the

U.S. Department of Energy

Office of Nuclear Energy

Under DOE Idaho Operations Office

Contract DE-AC07-05ID14517 


\section{ABSTRACT}

Many of the currently available and future electric vehicles can be fast charged, and, typically, at least $50 \%$ of the battery capacity can be returned in 15 to 20 minutes. This charge rate requires a power of at least 50 kilowatts, which can be expensive in terms of both infrastructure and electric utility demand charges. One potential way of minimizing this cost is to charge the electric vehicle with combined battery and grid power, thereby reducing the peak load on the grid. Many sizes and configurations are possible for such a battery. This study examines two possibilities: (1) a 20-kilowatt hour (kWh) battery energy storage (BES) system and (2) a 200-kWh BES system, as well as developing standard test procedures for assessing the suitability of battery technologies for use in such systems.

A simple characterization test on the battery candidates for the BES system was developed. Three lithium-based battery technologies (i.e., Sony/US26650FT, Panasonic/NCR18650, and A123/ANR26650MIA) were subjected to the test. The results suggested that the Sony/US26650FT and A123/ANR26650MIA battery technologies should outperform the Panasonic/NCR18650 battery technology for this application.

Two simulated laboratory profiles for assessing the longer-term performance of batteries operated under the BES system were developed and validated. The first simulated BES profile was based on a battery capacity of $20 \mathrm{kWh}$, while the second assumed a capacity of $200 \mathrm{kWh}$. A series of performance metrics were developed to assist with performance comparisons among the battery types undergoing the two profiles.

The three battery types were operated under the simulated 20-kWh BES profile for 3 months. The results obtained during this test period were consistent with those suggested by the screening test. The Sony/US26650FT and A123/ANR26650MIA battery technologies outperformed the Panasonic/NCR18650 battery technology. The Panasonic/NCR18650 battery technology failed after just 19 days, whereas the Sony/US26650FT and the A123/ANR26650MIA battery technologies were still delivering $88 \%$ and $86 \%$ of their initial capacities, respectively, at the end of the 3-month test. 


\section{CONTENTS}

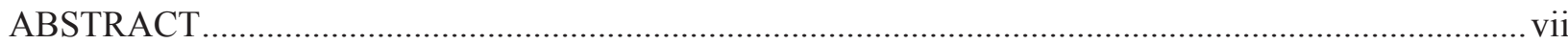

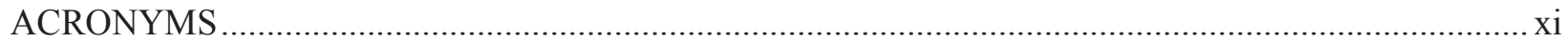

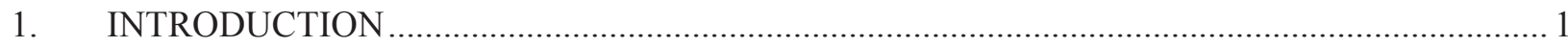

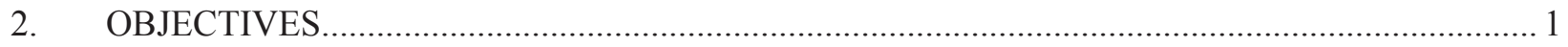

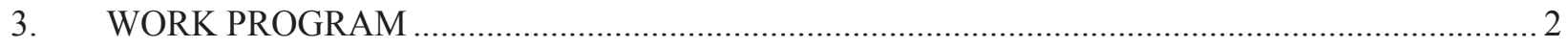

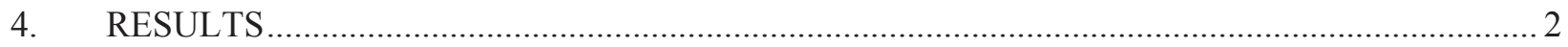

4.1 Task 3.14.1: Characterization Procedure for the Battery Energy Storage System

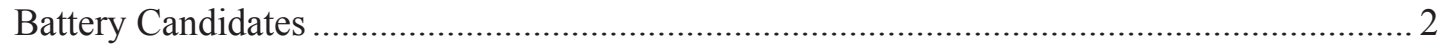

4.2 Task 3.14.2: Battery Selection and Validation................................................................. 2

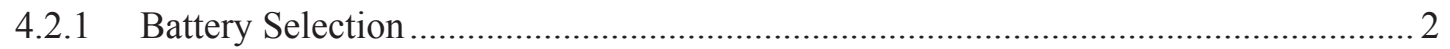

4.2.2 Internal Resistance at Various States of Charge ...................................................... 3

4.2.3 Discharge Performance at Different Rates of Discharge .......................................... 3

4.3 Task 3.14.3: Test Profile for Evaluating Battery Performance in a 20-kWh Battery

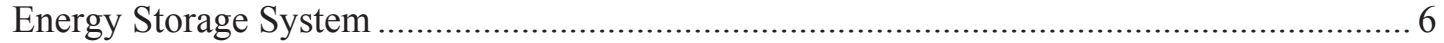

4.4 Task 3.14.4: Performance Metrics for Assessing the Battery Energy Storage System Battery Performance Under the 20-kWh Battery Energy Storage Profile .............................. 9

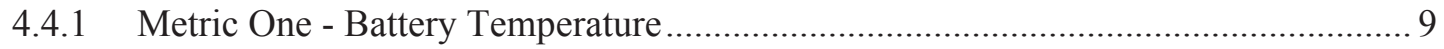

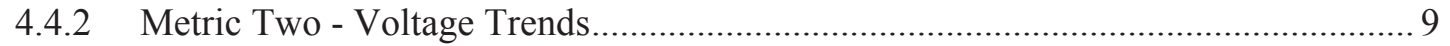

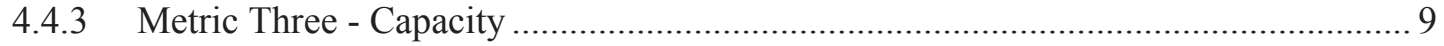

4.4.4 Metric Four - Operating Efficiency …….......................................................... 9

4.5 Task 3.14.5: Validation of the 20-kWh Battery Energy Storage Profile ............................. 9

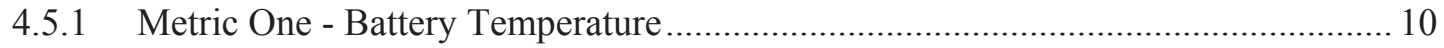

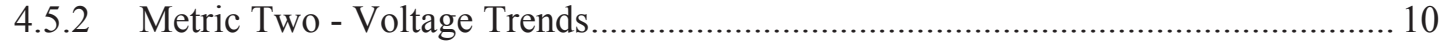

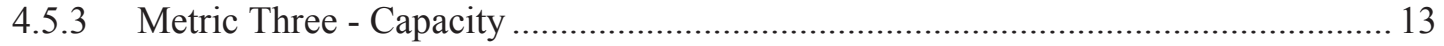

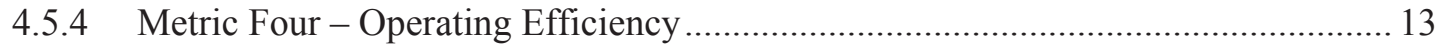

4.6 Task 3.14.6: Develop and Validate a Test Profile for Evaluating Battery

Performance in a 200-kWh Battery Energy Storage System .............................................. 14

4.6.1 Test Profile for Evaluating Battery Performance in a 200-kWh Battery

Energy Storage System ................................................................................... 14

4.6.2 Validation for the 200-kWh Battery Energy Storage Profile .................................... 14

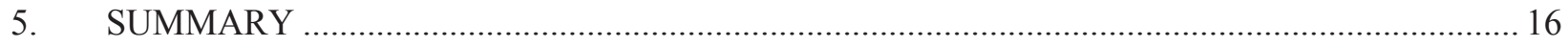

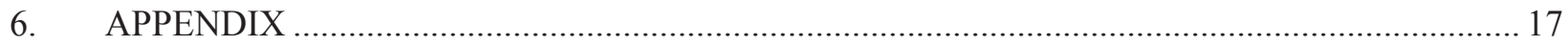




\section{FIGURES}

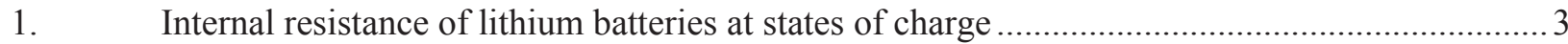

2. Sony/US26650FT cell - voltage and temperature during discharge $(0.5 \mathrm{C}, 1 \mathrm{C}, 1.5 \mathrm{C}$, and

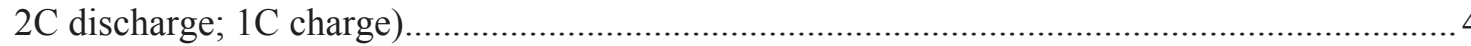

3. Panasonic/NCR18650 cell - voltage and temperature during discharge $(0.5 \mathrm{C}, 1 \mathrm{C}, 1.5 \mathrm{C}$,

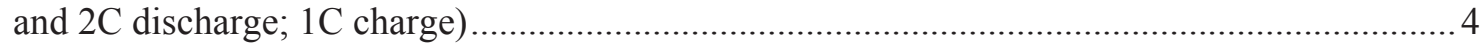

4. A123/ANR26650M1A cell - voltage and temperature during discharge $(0.5 \mathrm{C}, 1 \mathrm{C}$,

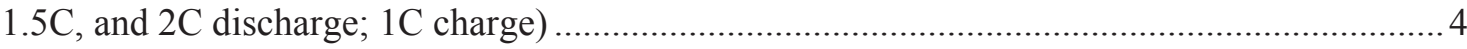

5. Discharge voltage of Sony/US26650FT battery at different rates .......................................... 5

6. Discharge voltage of Panasonic/NCR18650 battery at different rates ..................................... 5

7. Discharge voltage of A123/ANR26650M1A battery at different rates .................................. 6

8. Power profile for total power, battery, and grid contributions ........................................... 7

9. State of charge of the battery energy storage battery and vehicle battery during one day of real-time duty under the $20-\mathrm{kWh}$ battery energy storage profile .......................................... 8

10. Temperature of Sony/US26650FT, A123/ANR26650M1A, and Panasonic/NCR18650 battery technologies operating under the $20-\mathrm{kWh}$ battery energy storage profile. 10

11. Voltage of the A123/ANR26650M1A battery technology operating under the 20-kWh battery energy storage profile

12. Voltage of the Sony/US26650FT battery technology operating under the 20-kWh battery energy storage profile

13. Voltage of the Panasonic/NCR18650 battery technology operating under the 20-kWh battery energy storage profile

14. Short duration view of voltage of the A123 battery technology operating under the 20kWh battery energy storage profile

15. Short duration view of voltage and temperature of the Panasonic/NCR18650 battery technology operating under the $20-\mathrm{kWh}$ battery energy storage profile

16. Wh versus the Ah for the three battery technologies during operation under the $20-\mathrm{kWh}$ battery energy storage system.

17. Voltage of A123/ANR26650M1A battery technology operating under the 200-kWh battery energy storage profile (one day of simulated operation) 
18. Voltage of A123/ANR26650M1A battery technology operating under the 200-kWh battery energy storage profile

\section{TABLES}

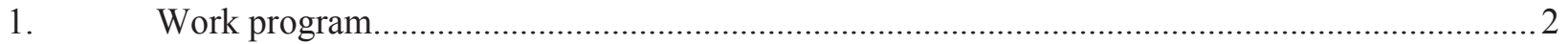

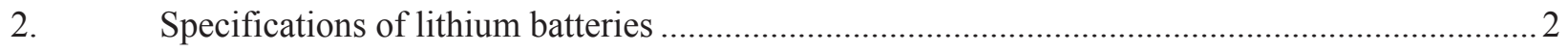

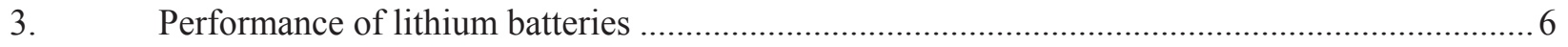

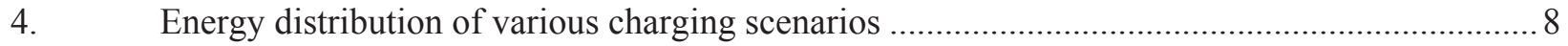

5. Capacity of normal batteries versus after 3 months of the 20-kWh battery energy

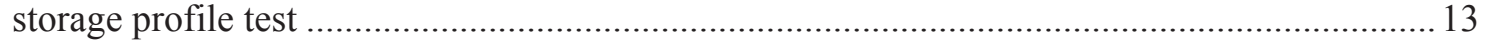

6. State of charge for the 200-kWh battery energy storage system during one duty day .............. 15 


\section{ACRONYMS}

$\begin{array}{ll}\text { Ah } & \text { ampere-hour } \\ \text { BES } & \text { battery energy storage } \\ \text { DC } & \text { direct current } \\ \text { DCFC } & \text { direct current fast charger } \\ \text { EODV } & \text { end-of-discharge voltage } \\ \text { EV } & \text { electric vehicle } \\ \text { kW } & \text { kilowatt } \\ \text { kWh } & \text { kilowatt hour } \\ \text { SOC } & \text { state of charge } \\ \text { TOCV } & \text { time-of-charge voltage } \\ \text { Wh } & \text { watt hour }\end{array}$




\section{Energy Storage for DC Fast Chargers Development and Demonstration of Operating Protocols for 20-kWh and 200-kWh Field Sites}

\section{INTRODUCTION}

Fast chargers for on-road electric vehicles (EVs), commonly defined as 50-kW or higher in-charge power and referred to as direct current (DC) Level 2 electric vehicle supply equipment units or DC fast charge (DCFC) units, are already in use. DCFC units will place a large power demand on the local electric grid. DCFC units that range from 40 to $120 \mathrm{~kW}$ are currently commercially available. The power demanded from DCFC units requires an expensive installation, typically requiring the electric utility to install a new metered service. Additionally, at this power level, most electric utilities implement demand charges that range from $\$ 10$ to $\$ 15$ per $\mathrm{kW}$ for each billing period. This could result in a monthly demand charge up to $\$ 1,200$ per month for a $60 \mathrm{~kW}$ DCFC unit. Assuming the DCFC unit completes five charges per day, the EV owners utilizing this DCFC unit will pay $\$ 4$ to $\$ 6$ per charge just to cover demand charges. This puts DCFC at a significant economic disadvantage, because a full recharge, using a less expensive alternating current Level 2 electric vehicle supply equipment unit at home, overnight, has no demand charges.

To reduce the demand that a DCFC unit places on the electric grid, local energy storage can be utilized to supply some, if not all, of the power and energy required for fast charging. This energy storage can be charged between supporting fast charge events at a slow rate in order to minimize power demand. This charging can occur immediately after discharge to ready the energy storage device for the next discharge (i.e., vehicle fast charge), it can occur at night (when demand on the grid is low), or during periods of high renewable energy availability, allowing a reduction in energy cost for charging and the increased absorption of renewables.

Battery energy storage (BES) systems present a viable means to implement DCFC unit demand reductions. Because the battery is stationary, neither gravimetric nor volumetric energy density is an issue. Further, vibration resistance and crash integrity are not important. However, the battery must be inexpensive and long-lived in order to effectively offset electric utility demand charges.

As a result of these benefits, DCFC units for on-road EVs that utilize energy storage will likely soon appear. However, no procedural methods currently exist to evaluate the performance of energy storage devices associated with on-road EV fast chargers. Therefore, two battery test cycles were developed for testing batteries in the laboratory, simulating likely daily use in the field. Idle time (when the battery is not operating during the cycle) was eliminated to accelerate the actual time needed to perform life-cycle testing on the battery. The test cycles were derived based on maximum power and energy values that a complete battery pack would require to support fast charging. The profiles were then verified, with the most promising used for a 3-month test, on three different battery technologies (note: these battery types were first subjected to a simple characterization procedure that was designed to identify unsuitable technologies). This testing yielded information on how each evaluated battery technology reacted to the proposed test cycle and on the ability of the test cycle to quantify battery performance in the BES system.

\section{OBJECTIVES}

The objectives of the program of work are as follows:

- Develop laboratory test procedures for evaluating the performance of a DCFC BES system.

- Validate the test procedures using different lithium battery technologies and obtain preliminary information on how effective DCFC units are at mitigating the electric utility demand charges for DC fast charging. 


\section{WORK PROGRAM}

The tasks of the work program are described in Table 1.

Table 1. Work program.

Task Requirement

Task 3.14.1 Develop characterization procedure for the battery candidates and validate

Task 3.14.2 Select and validate three lithium battery technologies

Task 3.14.3 Develop a longer-term test procedure for the 20-kWh BES system

Task 3.14.4 Develop performance metrics for battery evaluation under the 20-kWh BES profile

Task 3.14.5 Cycle three lithium battery technologies under the 20-kWh BES profile for 3 months

Task 3.14.6 Develop a longer-term test procedure for the 200-kWh BES system

\section{RESULTS \\ 4.1 Task 3.14.1: Characterization Procedure for the Battery Energy Storage System Battery Candidates}

Life testing of batteries is a time-consuming and expensive process. Therefore, a simple characterization procedure that helps predict the battery's performance when used to fast charge EVs (in conjunction with the grid) was developed. The method is predictive in nature, does not involve life cycling of batteries and can provide useful information in a matter of days.

The characterization procedure for the BES system battery candidates is detailed as follows (refer to Appendix for battery test specifications):

(a) Selected and assembled a string or individual cells; the cells were open to the atmosphere with no insulating effect from packaging.

(b) Measured internal resistance over the entire range of state of charge (SOC).

(c) Measured discharge performance at various rates (e.g., $0.5 \mathrm{C}, 1 \mathrm{C}, 1.5 \mathrm{C}$, and $2 \mathrm{C}$ ) using a $1 \mathrm{C}$ charge rate, while monitoring cell temperature (ambient temperature was maintained at $25^{\circ} \mathrm{C}$ ).

\subsection{Task 3.14.2: Battery Selection and Validation}

\subsubsection{Battery Selection}

Three lithium battery technologies were selected for the procedure validation study. Their specifications are summarized in Table 2. It can be seen that the capacity of the cells was between 2.3 and 2.85 ampere-hour (Ah) and the nominal voltages varied between 3.2 and 3.6 volts.

Table 2. Specifications of lithium batteries.

\begin{tabular}{lccc}
\hline & Sony & $\mathrm{A} 123$ & Panasonic \\
\hline Chemistry & $\mathrm{LiFePO}_{4}$ & $\mathrm{LiFePO}_{4}$ & $\mathrm{Li} \mathrm{Ni} / \mathrm{Al} / \mathrm{Co}$ \\
Model & $\mathrm{US} 26650 \mathrm{FT}$ & $\mathrm{ANR} 26650 \mathrm{M} 1 \mathrm{~A}$ & $\mathrm{NCR} 18650$ \\
Nominal voltage & 3.2 & 3.3 & 3.6 \\
Rated capacity (Ah) & 2.85 & 2.3 & 2.75 \\
Top-of-charge voltage & 3.6 & 3.6 & 4.2 \\
Charging cutoff current (A) & 0.1 & 0.1 & 0.55 \\
End-of-Discharge voltage & 2.0 & 2.0 & 2.5 \\
\hline
\end{tabular}




\subsubsection{Internal Resistance at Various States of Charge}

The internal resistance of the three battery technologies was measured at a range of SOCs and the results are summarized in Figure 1. The internal resistances of both the Sony/US26650FT and the A123/ANR26650MIA batteries are similar, whereas that of the Panasonic/NCR18650 unit is much higher. This result suggested that the Panasonic/NCR18650 unit may be more susceptible to heating than the other battery types at high rates of discharge.

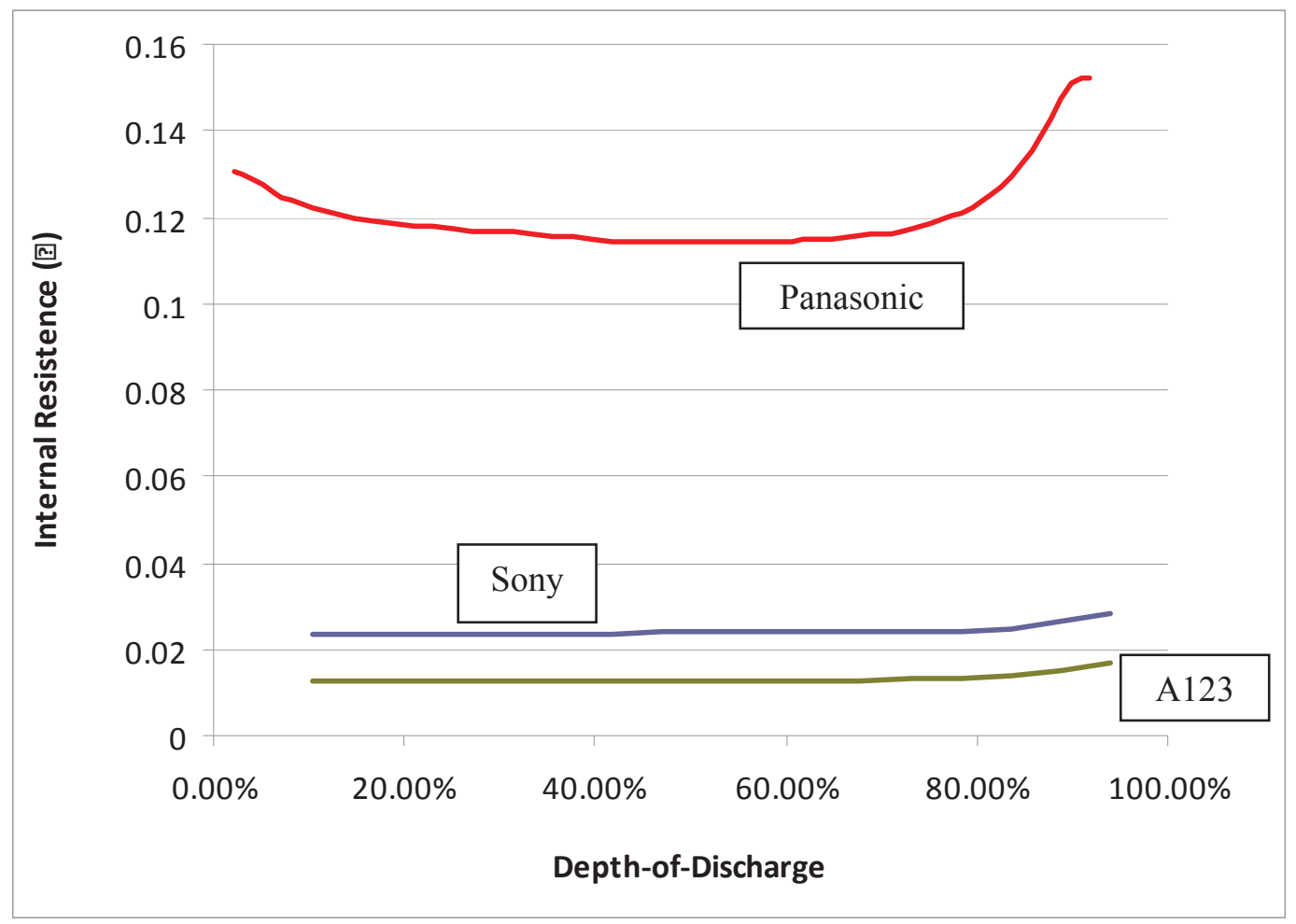

Figure 1. Internal resistance of lithium batteries at states of charge.

\subsubsection{Discharge Performance at Different Rates of Discharge}

The discharge performance of the three battery technologies is shown in Figures 2 through 7 and Table 3 (note: the discharge rate varied from 0.5 to $2 \mathrm{C}$, but all charging was conducted at $1 \mathrm{C}$ ).

The capacity (measured in $\mathrm{Ah}$ ) of the three battery technologies did not change as the discharge rate increased (Table 3). However, the energy (measured in Wh) available from the Panasonic/NCR18650 battery technology dropped significantly at higher rates relative to that of the other battery technologies. This behavior is consistent with the recorded discharge voltage, where the Panasonic/NCR18650 battery technology dropped faster than the other variants (Figures 5 through 7). Further, the operating temperature of the Panasonic/NCR18650 battery technology was considerably higher than that of the others (Figures 2 through 4 ). These results are supported by the internal resistance measurements, which suggest that the Panasonic/NCR18650 battery technology is more susceptible to heating than the other two types (Figure 1).

In summary, the relatively higher operating temperatures, voltage drop, and internal resistance of the Panasonic/NCR18650 battery technology suggested that it was not as well suited to a high-rate BES system compared to the Sony/US26650FT and A123/ANR26650MIA battery technologies. 


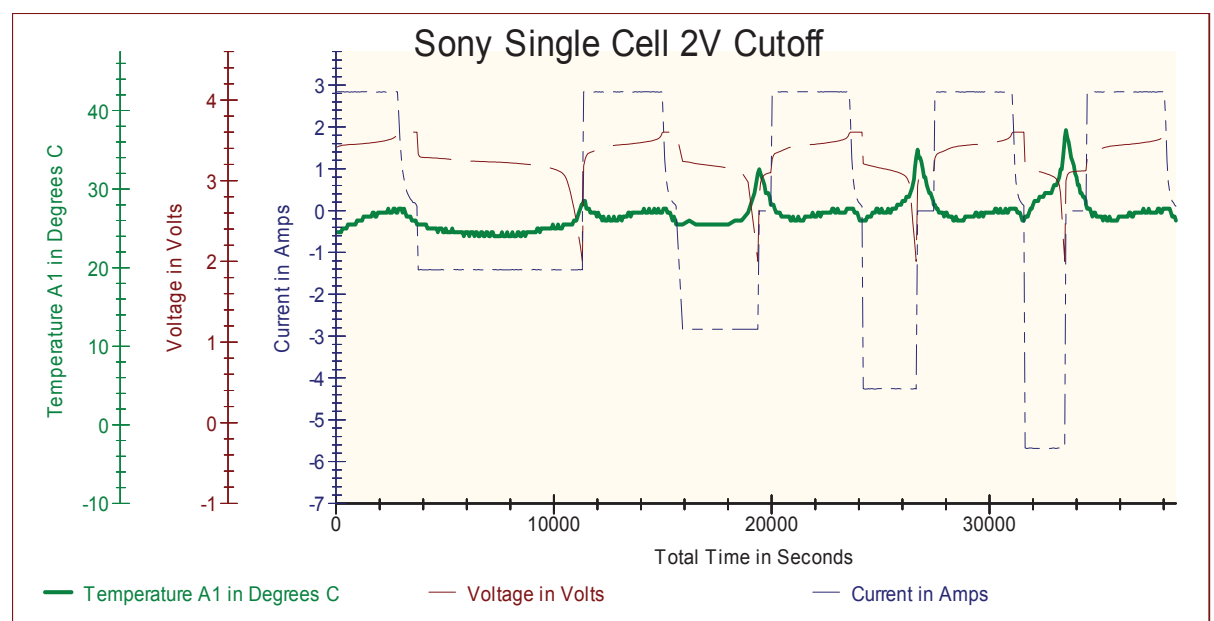

Figure 2. Sony/US26650FT cell - voltage and temperature during discharge $(0.5 \mathrm{C}, 1 \mathrm{C}, 1.5 \mathrm{C}$, and $2 \mathrm{C}$ discharge; $1 \mathrm{C}$ charge).

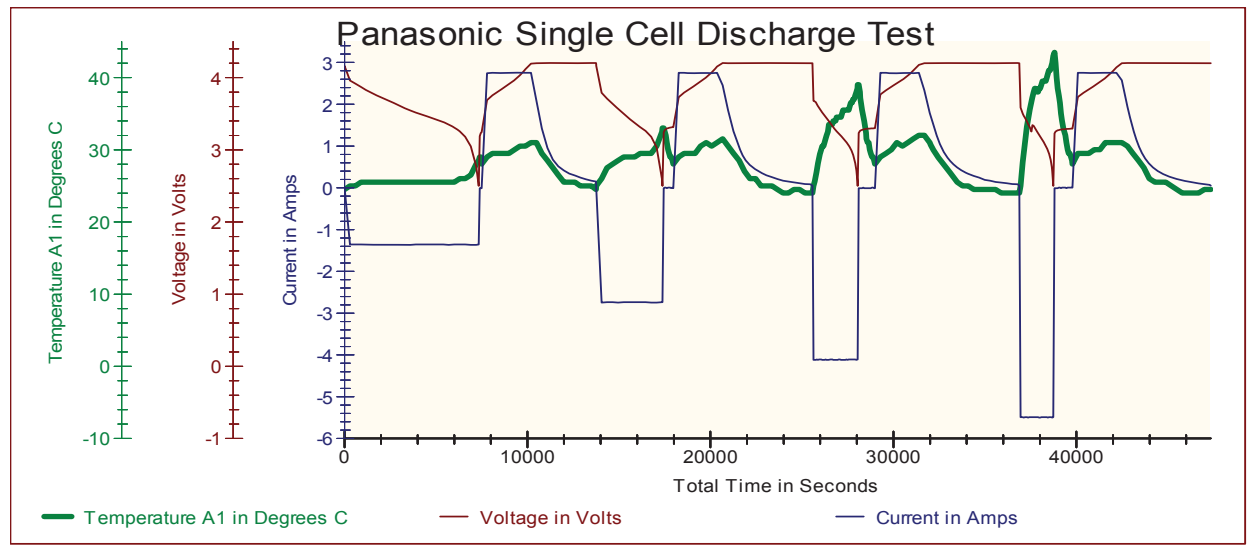

Figure 3. Panasonic/NCR18650 cell - voltage and temperature during discharge $(0.5 \mathrm{C}, 1 \mathrm{C}, 1.5 \mathrm{C}$, and $2 \mathrm{C}$ discharge; 1C charge).

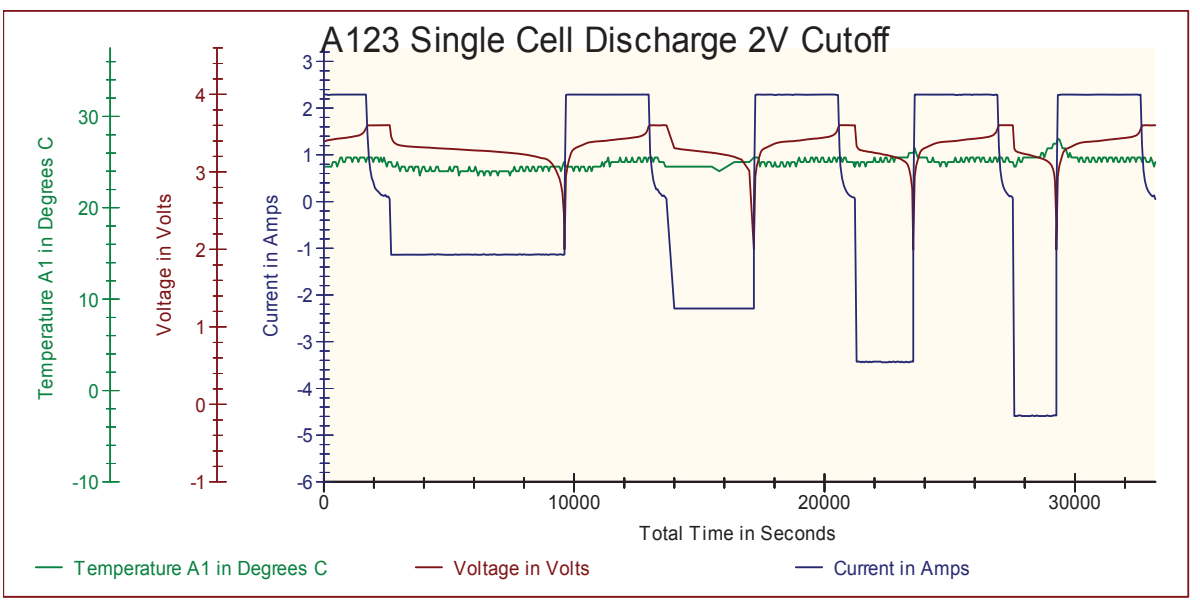

Figure 4. A123/ANR26650M1A cell - voltage and temperature during discharge $(0.5 \mathrm{C}, 1 \mathrm{C}, 1.5 \mathrm{C}$, and $2 \mathrm{C}$ discharge; $1 \mathrm{C}$ charge). 


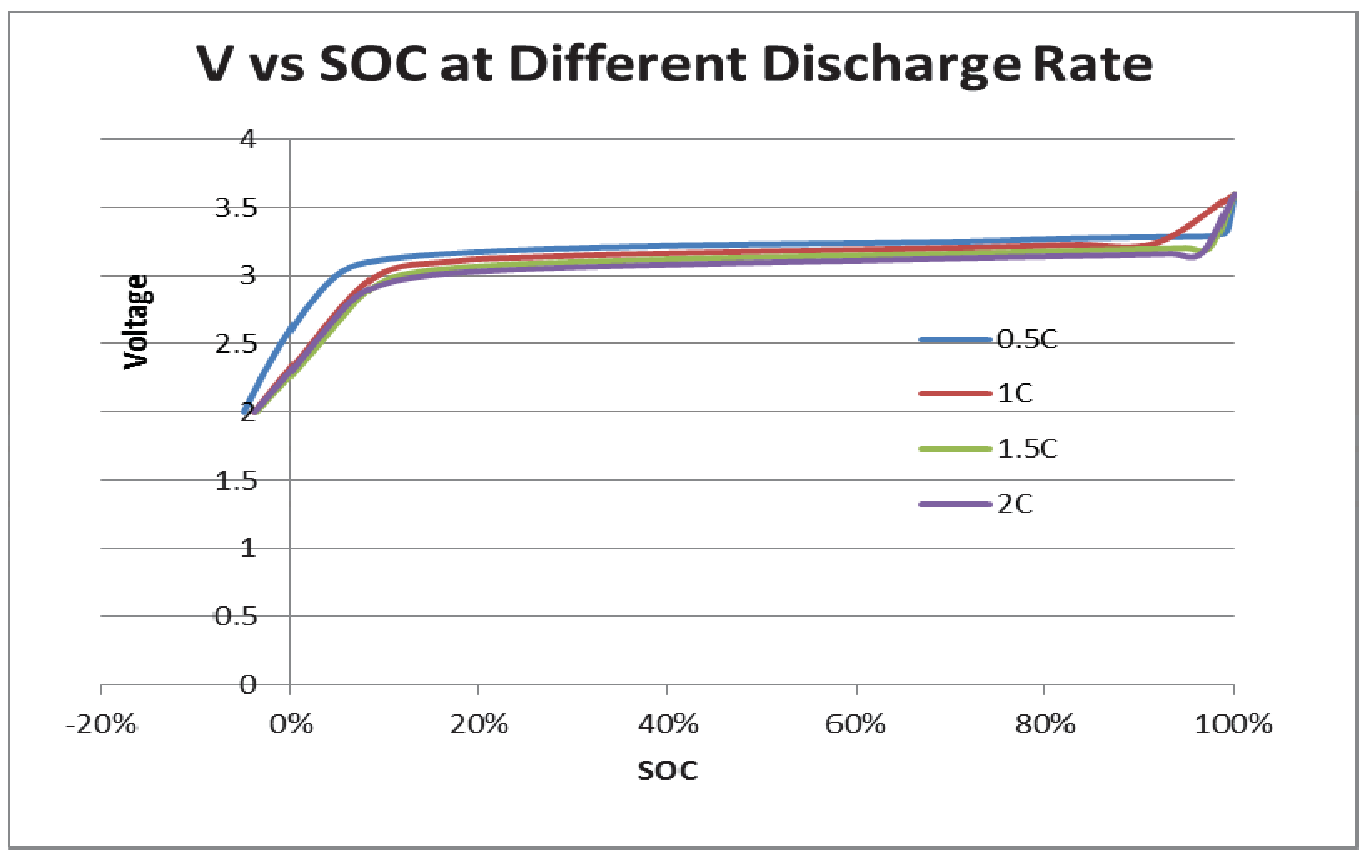

Figure 5. Discharge voltage of Sony/US26650FT battery at different rates.

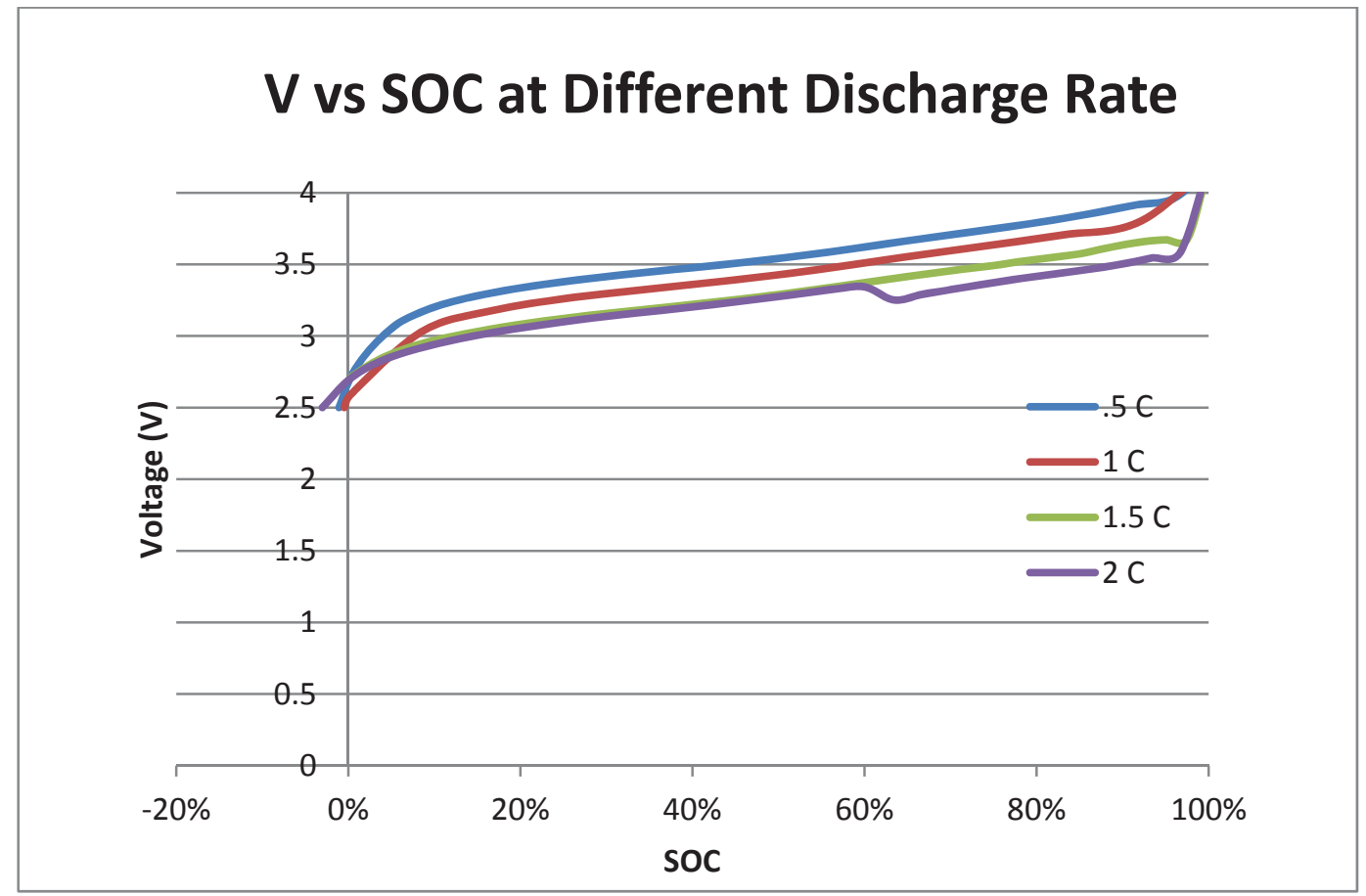

Figure 6. Discharge voltage of Panasonic/NCR18650 battery at different rates. 


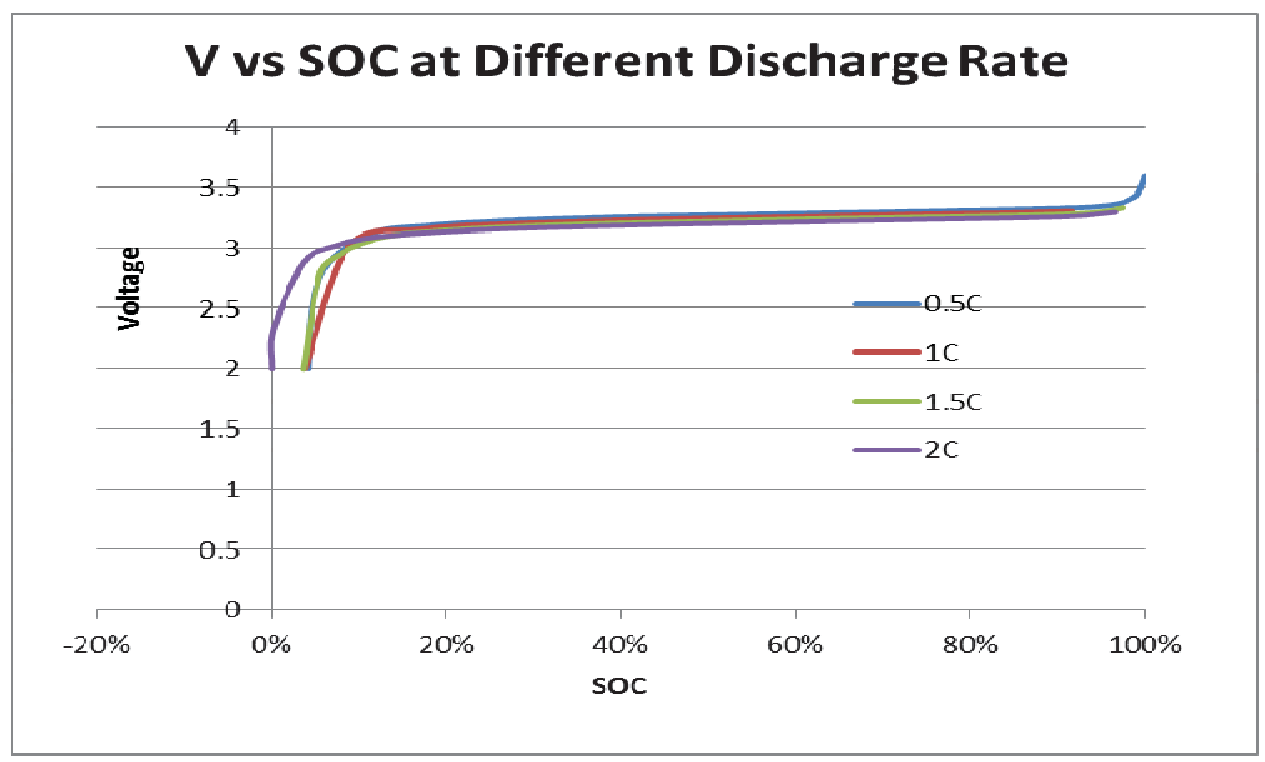

Figure 7. Discharge voltage of A123/ANR26650M1A battery at different rates.

Table 3. Performance of lithium batteries.

\begin{tabular}{lccc}
\hline & Sony & Panasonic & A123 \\
\hline Discharge Rate & Measured Discharge Capacity $(\mathrm{Ah})$ \\
0.5C discharge rate & -3.0 & -2.8 & -2.2 \\
1C discharge rate & -3.0 & -2.8 & -2.2 \\
1.5C discharge rate & -3.0 & -2.8 & -2.2 \\
2C discharge rate & -3.0 & -2.8 & -2.2 \\
& Measured & 1C Charge Return (Ah) \\
1C charge rate & 3.0 & 2.8 & 2.2 \\
& Measured Discharge Energy $(\mathrm{Wh})$ \\
0.5C discharge rate & -9.2 & -9.7 & -7.0 \\
1C discharge rate & -9.1 & -9.4 & -7.0 \\
1.5C discharge rate & -9.0 & -9.2 & -7.0 \\
2C discharge rate & -8.9 & -9.1 & -7.0 \\
& Measured Charge Energy (Wh) \\
1C charge rate & 10.1 & 11.1 & 7.4 \\
& \multicolumn{3}{|c}{} \\
Energy density (Wh/kg) & 107.5 & 205.7 & 100.7 \\
Cell efficiency & $90 \%$ & $84 \%$ & $95 \%$ \\
\hline
\end{tabular}

\subsection{Task 3.14.3: Test Profile for Evaluating Battery Performance in a 20-kWh Battery Energy Storage System}

A BES system employed to assist the electric grid to recharge EVs will experience a wide range of operating conditions, including the number of vehicles to be charged per day and the level of recharge required for each vehicle. At one end of the scale, there may be only a few EVs requiring a minor daily recharge (i.e., $30 \%$ of battery capacity), with recharges spread out evenly throughout the day. At the other 
extreme, many EVs may require a moderate daily recharge (i.e., $60 \%$ of battery capacity) during peak travel times, requiring large energy charges with short periods between charges. Obviously, this latter example would reduce the lifetime of the BES system compared to that of the lighter duty. The profile developed in this study was designed to fall somewhere between these two scenarios, which represents a realistic scenario for a medium-use BES system supporting an EV fast charge station. It also was based on ECOtality's experience with partial-SOC operation.

The procedure developed, termed the 20-kWh BES profile, assumes that the BES system has a capacity of $20 \mathrm{kWh}$ and that the EV battery being charged has a capacity of $24 \mathrm{kWh}$. It also assumes that the electric grid could contribute a continuous $20 \mathrm{~kW}$ with the BES system supplementing up to $30 \mathrm{~kW}$. When a battery is charged, the charge power is not constant throughout the charge and begins to drop off in an approximately linear fashion near the end of the charge (Figure 8). In this case, the battery contribution decreased when the charge power decreased, while the grid contribution initially remained unchanged, eventually the grid contribution decreased along with the total charge power.

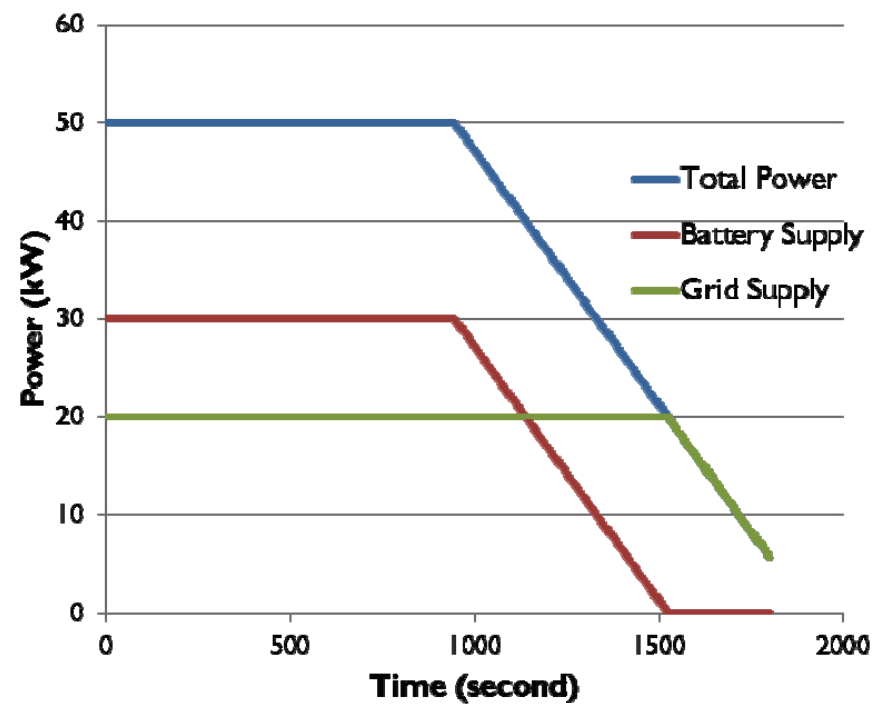

Figure 8. Power profile for total power, battery, and grid contributions.

Therefore, a $50-\mathrm{kW}$ total is available during recharge, which corresponds to a maximum discharge rate for the BES system at $1.5 \mathrm{C}$. It is important to note that the vehicle recharging algorithm is controlled by the vehicle's battery management system and not by the electric vehicle supply equipment unit. In this example, charging enters the voltage control regime at a SOC of around $60 \%$. However, this power tapering point varies depending on the vehicle type, ambient temperature, and vehicle conditions.

The 20-kWh BES profile is shown schematically in Figure 9. The SOC of the BES system at the commencement of charging is shown in red (rectangle box) and the corresponding SOC range of the vehicle battery being charged is shown in black (oval box) (note: rests between charging and discharging are minimized to allow a complete 24-hour day to be compressed into approximately 6 hours).

The two charging scenarios are shown in Table 4. As displayed in Figure 9, the BES system started the day at $100 \%$ SOC. It then charged a vehicle battery from 30 to $90 \%$ SOC (required approximately $5.9 \mathrm{kWh}$ from the BES system and took 24.6 minutes). In the process, the BES system was discharged at a $1.5 \mathrm{C}$ rate from 100 to $70 \% \mathrm{SOC}$. The second vehicle then came in and its battery was charged from 30 to $60 \% \mathrm{SOC}$ (required approximately $4.3 \mathrm{kWh}$ and took 8.6 minutes), during which time the BES system battery was discharged from 70 to $48 \%$. The BES system battery was then recharged from 48 to $70 \%$ from the main grid at a $1 \mathrm{C}$ rate and was then ready to charge the next vehicle battery. 


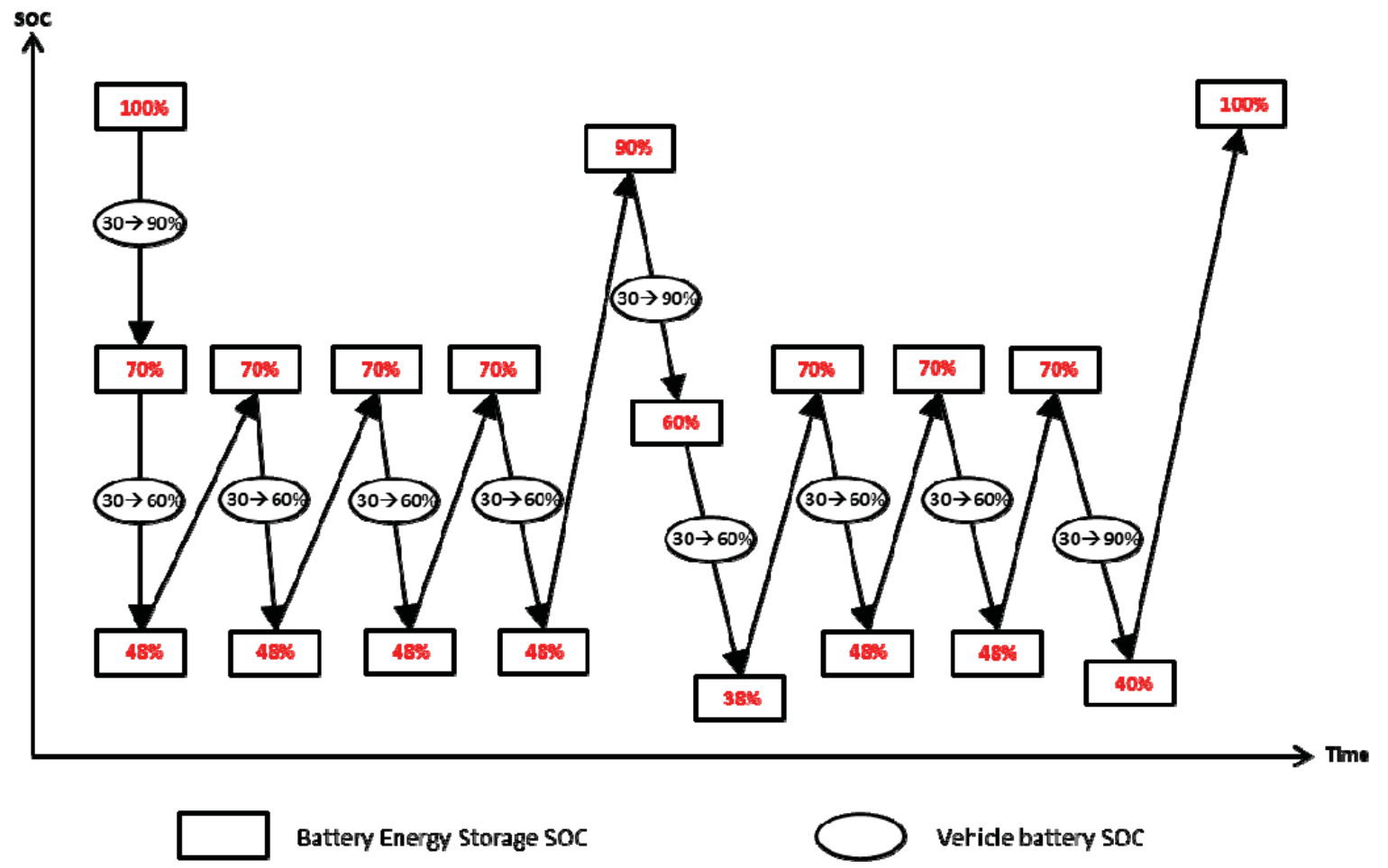

Figure 9. State of charge of the battery energy storage battery and vehicle battery during one day of real-time duty under the $20-\mathrm{kWh}$ battery energy storage profile.

Table 4. Energy distribution of various charging scenarios.

\begin{tabular}{cccccc}
\hline $\begin{array}{c}\text { Vehicle } \\
\text { Battery SOC }\end{array}$ & $\begin{array}{c}\text { Total Energy } \\
\text { Required (kWh) }\end{array}$ & $\begin{array}{c}\text { Energy from } \\
\text { Battery }(\mathrm{kWh})\end{array}$ & $\begin{array}{c}\text { Energy from } \\
\text { Grid }(\mathrm{kWh})\end{array}$ & $\begin{array}{c}\text { BES System } \\
\text { Battery SOC } \\
\text { Discharge }\end{array}$ & $\begin{array}{c}\text { Estimated } \\
\text { Charging Time } \\
\text { (minutes) }\end{array}$ \\
\hline 30 to $60 \%$ & 7.2 & 4.3 & 2.9 & $22 \%$ & 8.6 \\
30 to $90 \% *$ & 11.6 & 5.9 & 5.7 & $30 \%$ & 24.6 \\
\hline
\end{tabular}

* The 30 to $90 \%$ charge data were based on true field test data. The total vehicle battery capacity was $19.3 \mathrm{kWh}$, which is the actual usable capacity, based on the vehicle battery management system calculation for this particular test.

This pattern of vehicle charge/BES system discharge, followed by a partial recharge of the BES system from the grid, continued until a total of 10 vehicles were charged, which was considered to simulate the duty cycle of one single day. The BES system battery was then fully recharged overnight in readiness for the next day.

As mentioned above, one 6-hour pass through the simulated profile represented 24 hours of duty in the field and provided a time-compression factor of 4:1. It is likely that such a time compression would increase the BES system temperature more than experienced in the field, because during normal duty, the field BES system would experience more rest periods. This situation was an unfortunate side effect of simulations that speed up real-time duty and resulted in shorter lifetimes. However, provided that such simulations are controlled appropriately, useful information is provided on the relative performances of different technologies. 


\subsection{Task 3.14.4: Performance Metrics for Assessing the Battery Energy Storage System Battery Performance Under the 20-kWh Battery Energy Storage Profile}

A series of metrics were identified to provide accurate performance comparisons of different BES system battery technologies operated under the 20-kWh BES profile. These metrics are described in Sections 4.4.1 through 4.4.4.

\subsubsection{Metric One - Battery Temperature}

The BES system was designed to operate with passive cooling only (i.e., without any air conditioning). Because battery lifetime generally decreases with increasing temperature, and high ambient temperatures are expected in many locations in the summer months, it is important that BES systems experience minimal heating as a result of the actual operating schedule. Accordingly, battery temperature was included as a metric in this study and is presented simply as single lines of data on an $\mathrm{x}-\mathrm{y}$ graph. Further, temperature limits were provided by the battery manufacturers and programmed into the test cycle. Battery operations were halted if the temperature exceeded the manufacturer's temperature limits. Cycling was restarted when the battery temperature dropped to a lower level. The rise in battery temperature, especially if it occurred continuously during the test cycle, was closely monitored to determine the termination point of the testing.

\subsubsection{Metric Two - Voltage Trends}

Two voltage parameters that can be used to gauge battery performance are the lowest voltage and the highest voltage observed during a particular duty cycle. The lowest voltage will occur at the end of most severe discharge step and is known as the end-of-discharge voltage (EODV). Similarly, the highest voltage will occur at the end of one of the designated charges and is known as the top-of-charge voltage (TOCV). If monitored continuously, these two voltages can provide useful comparisons between different battery technologies. Accordingly, EODV and TOCV were recorded for the duration of the testing.

\subsubsection{Metric Three - Capacity}

Changes in capacity recorded at a standard rate also were useful for determining the rate of performance loss. Therefore, the battery capacity was tested periodically at a standard rate and was recorded during operation under the 20-kW BES profile.

\subsubsection{Metric Four - Operating Efficiency}

The operating efficiency of batteries is an important parameter, because it provides information on the energy requirements and costs during operation, which often change as batteries age. In this study, the operating efficiency was obtained by plotting Wh versus Ah over each pass through of the 20-kW BES profile. Because the duty was scaled as if the module was performing in an entire pack, the Wh versus Ah chart provided a very simple, visual guide showing the battery wasted more energy during both charge and discharge over the entire screening test period. Also, how thick the line is tells us if the efficiency changed during the test. A thin line means the values are the same for each cycle and experienced no change. A thick line means the efficiency changed noticeably.

\subsection{Task 3.14.5: Validation of the 20-kWh Battery Energy Storage Profile}

The following three lithium battery technologies were operated under the 20-kWh profile and the results are summarized in terms of the performance metrics described in Section 4.4. The Sony/US26650FT and A123/ANR26650MIA battery technologies performed well for the 3-month cycling period, but the Panasonic/NCR18650 battery technology failed after just 19 days. 
- A123/ANR26650MIA lithium ion phosphate - 2.3 Ah cell

- Sony/US26650FT lithium ion phosphate - 2.85 Ah cell

- Panasonic/NCR18650 - 2.75 Ah cell.

\subsubsection{Metric One - Battery Temperature}

The naked cells were operated in the laboratory (without any packaging) at an ambient temperature of $25^{\circ} \mathrm{C}$. Thus, the observed operating temperatures are considered to represent the average ambient temperatures likely to be encountered in the field.

The temperatures of the three batteries during cycling are summarized in Figure 10. The temperatures of both the Sony/US26650FT and A123/ANR26650MIA battery technologies are very similar and remained constant during the 3-month cycling period. In addition, the temperature increased as a result of cycling by only $2^{\circ} \mathrm{C}$. By contrast, the temperature of the Panasonic/NCR 18650 battery technology increased by more than $15^{\circ} \mathrm{C}$ in 19 days. This increase is considered excessive. Because it is planned to operate the BES system with passive cooling (i.e., no air conditioning) at an ambient temperature of $40^{\circ} \mathrm{C}$, the operating temperature of the Panasonic/NCR 18650 battery technology would be at least $55^{\circ} \mathrm{C}$ in less than 20 days of operation. Obviously, this technology is not considered suitable for continuous high-rate operation. Therefore, it is recommended for the test profile that the temperature rise during the BES duty cycle be limited to a $10^{\circ} \mathrm{C}$ increase, especially if the battery temperature gives a trend of a steady, continuous increase.

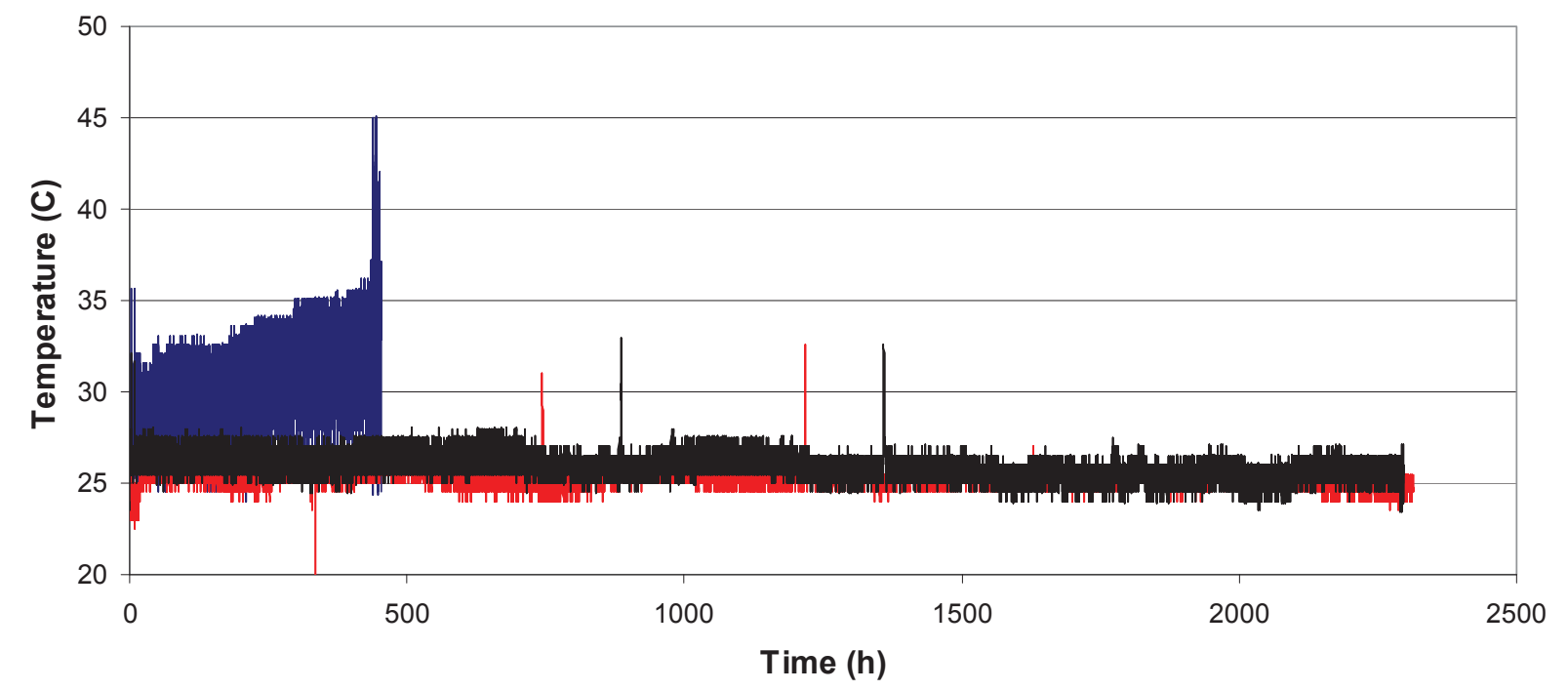

Figure 10. Temperature of Sony/US26650FT (Black Line), A123/ANR26650M1A (Red Line), and Panasonic/NCR18650 (Blue Line) battery technologies operating under the 20-kWh battery energy storage profile.

\subsubsection{Metric Two - Voltage Trends}

How the operating voltage of a battery subjected to repetitive cycling changes with time provides important information on performance of the technology. A convenient way to analyze this trend is to record TOCV and EODV. This information was collected for the A123/ANR26650MIA, Sony/US26650FT, and Panasonic/NCR18650 battery technologies and is summarized in Figures 11 through 13. At the start of duty, the extent of the voltage spread (i.e., TOCV-EODV, designated as $\Delta \mathrm{V}$ ) was smallest for the A123/ANR26650MIA battery technology (Figure 11) and largest for the Panasonic/NCR18650 battery technology (Figure 13). As cycling progressed, the $\Delta \mathrm{V}$ of the 
A123/ANR26650MIA and the Sony/US26650FT battery technologies remained relatively constant, whereas that of the Panasonic/NCR18650 battery technology increased quickly. This trend continued until the Panasonic/NCR18650 battery technology failed to maintain EODV above the manufacturer recommended discharge voltage limit after just 19 days of duty. Figures 14 and 15 show the short duration view of the voltage profile for the A123/ANR26650MIA and Panasonic/NCR18650 battery technologies operating under the BES profile.

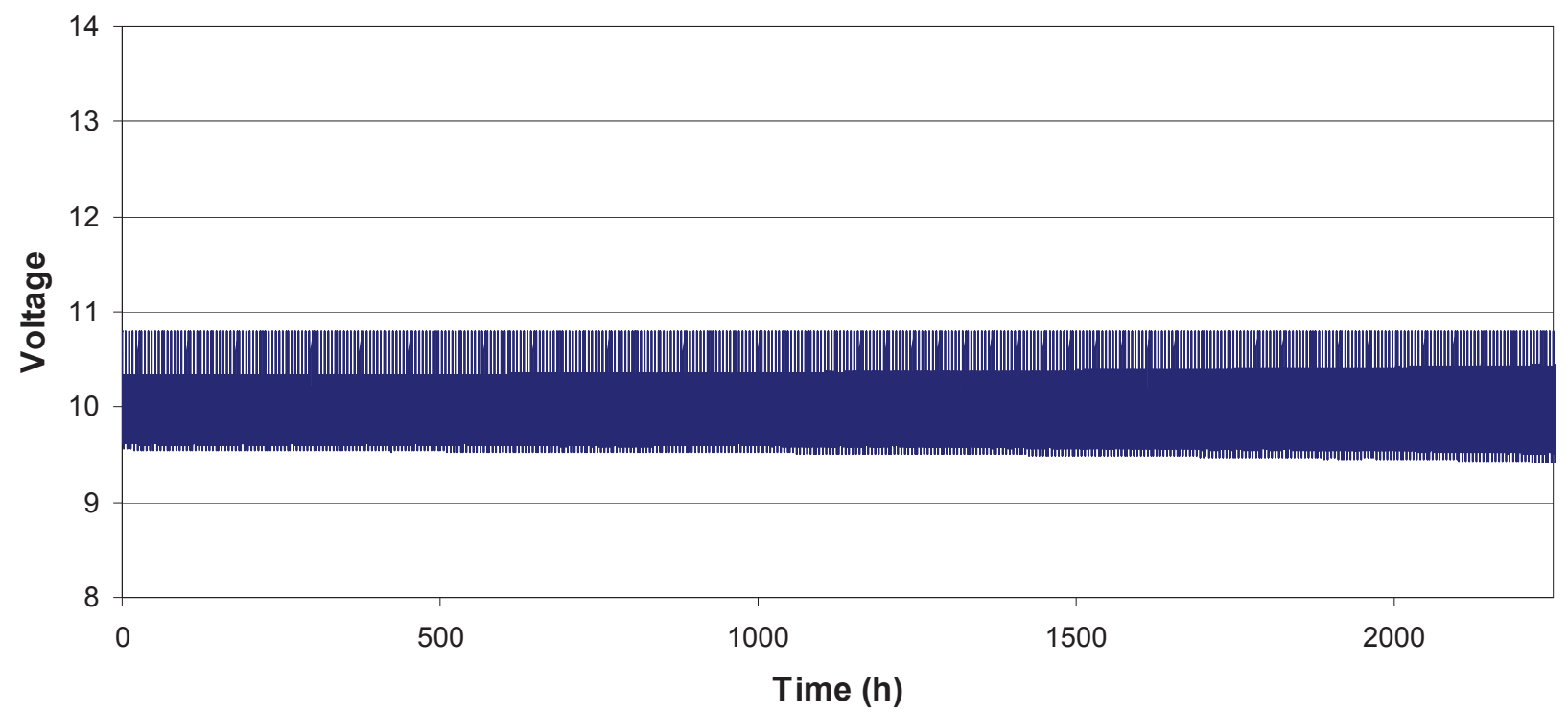

Figure 11. Voltage of the A123/ANR26650M1A battery technology operating under the 20-kWh battery energy storage profile.

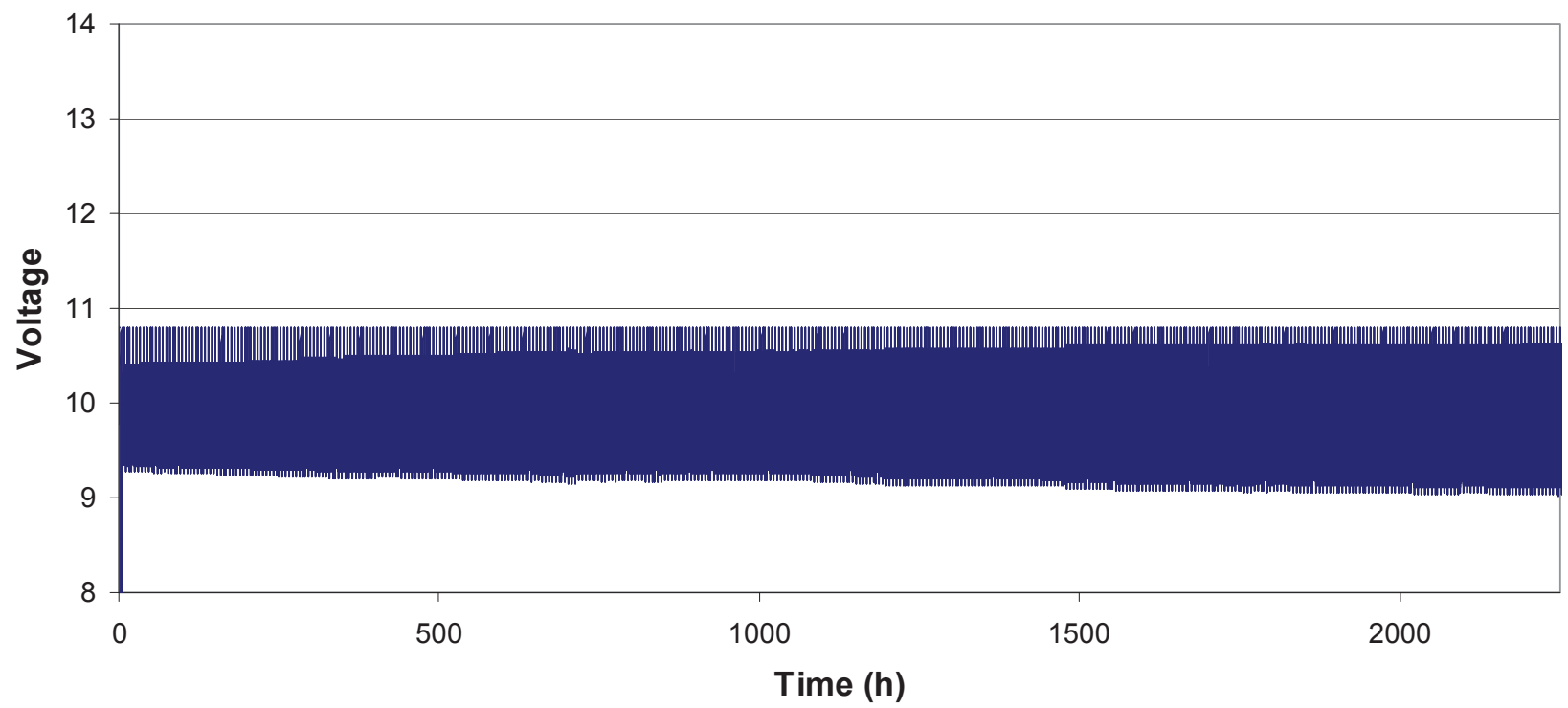

Figure 12. Voltage of the Sony/US26650FT battery technology operating under the 20-kWh battery energy storage profile. 


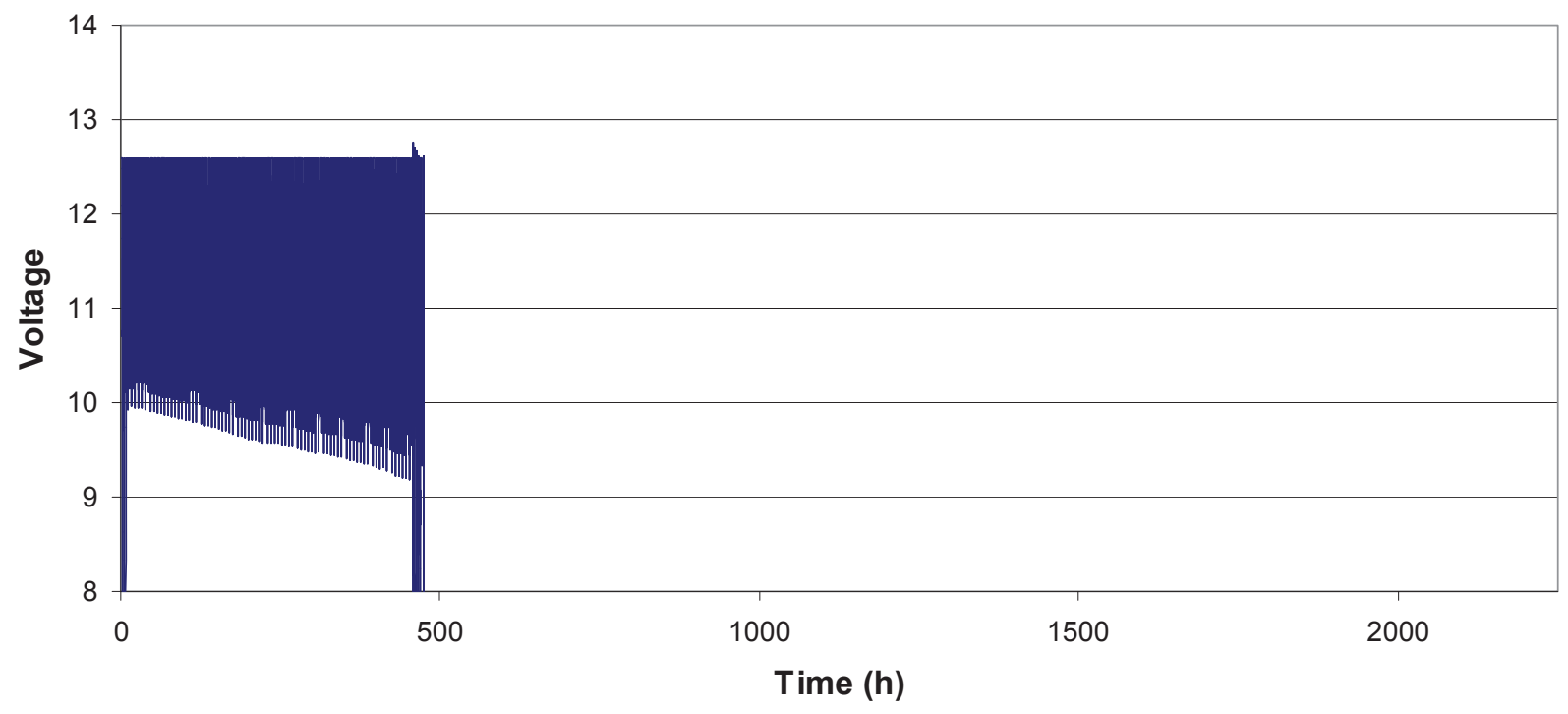

Figure 13. Voltage of the Panasonic/NCR18650 battery technology operating under the 20-kWh battery energy storage profile.

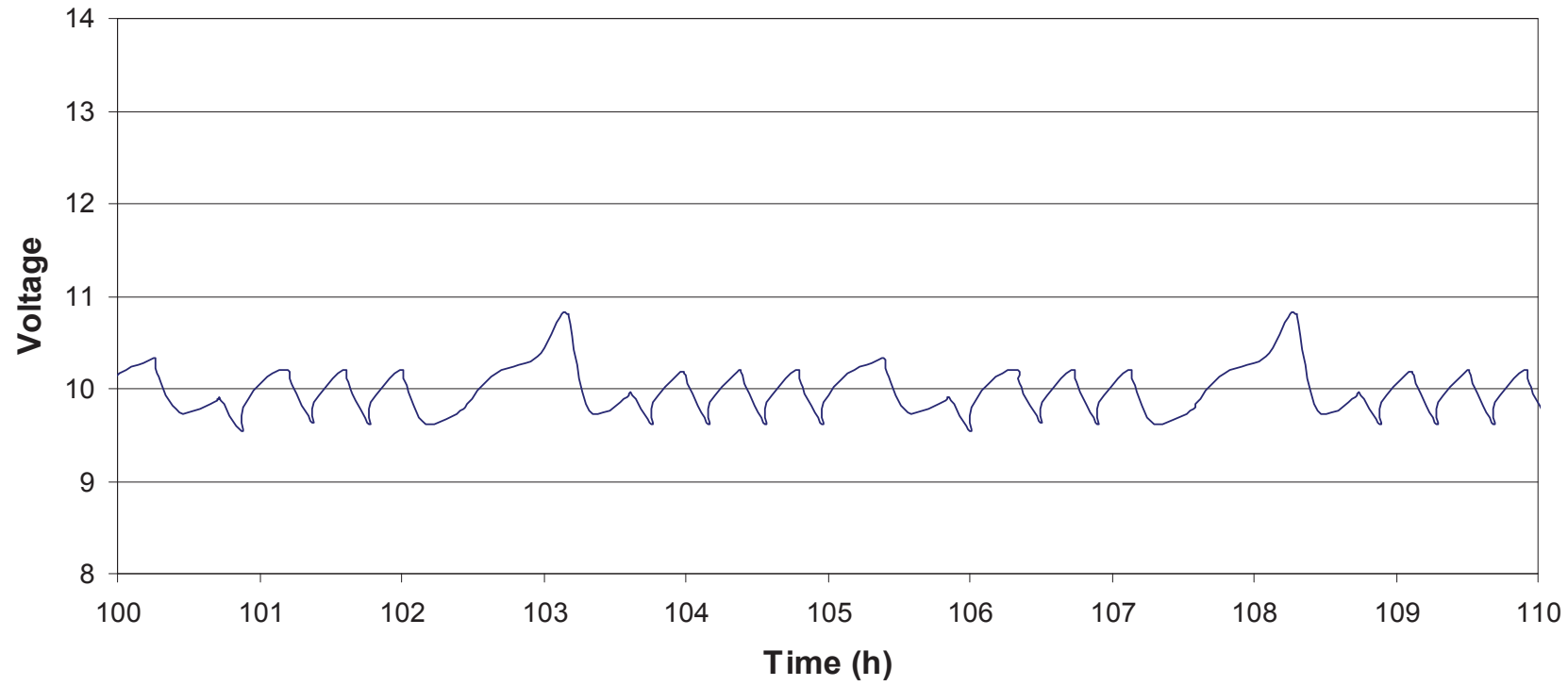

Figure 14. Short duration view of voltage of the A123 battery technology operating under the $20-\mathrm{kWh}$ battery energy storage profile. 


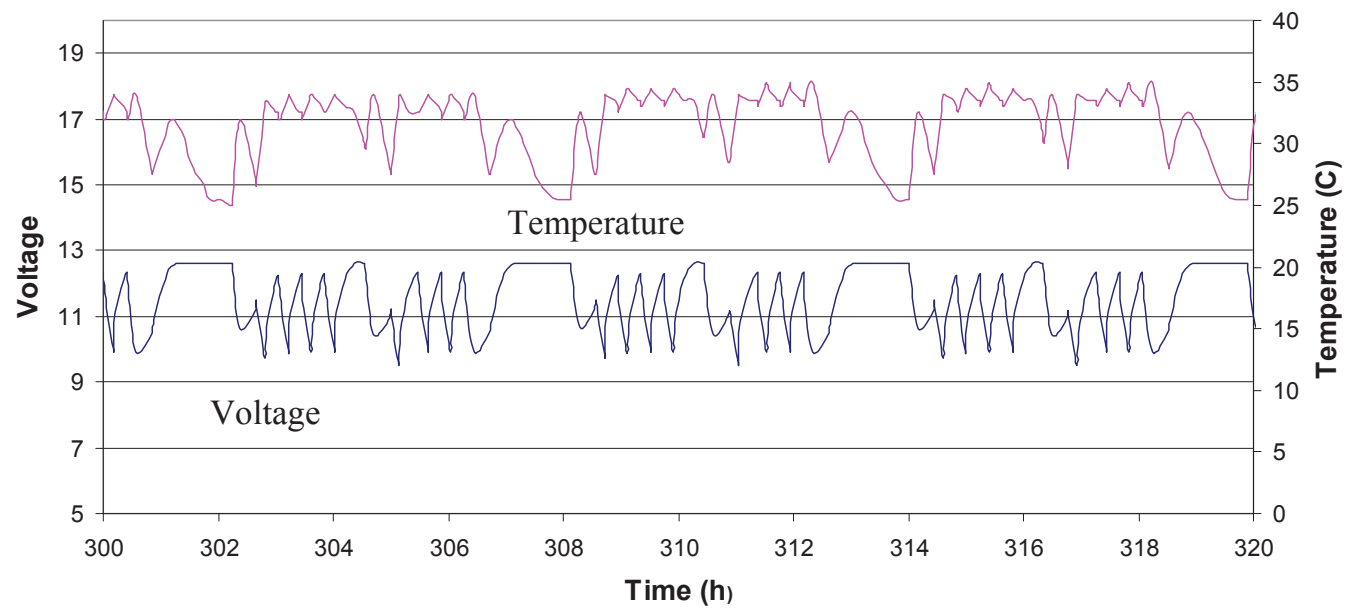

Figure 15. Short duration view of voltage and temperature of the Panasonic/NCR18650 battery technology operating under the $20-\mathrm{kWh}$ battery energy storage profile.

\subsubsection{Metric Three - Capacity}

The battery capacity was tested periodically at a standard rate. The capacity (1C rate) of the technologies after cycling is shown in Table 5. It should be noted that the A123/ANR26650MIA and Sony/US26650FT battery technologies experienced a similar level of degradation after 3 months of cycling ( $86 \%$ and $88 \%$ of initial capacity, respectively), but the Panasonic/NCR18650 battery technology dropped to $72 \%$ after just 19 days.

Table 5. Capacity of normal batteries versus after 3 months of the $20-\mathrm{kWh}$ battery energy storage profile test.

\begin{tabular}{lcccc}
\hline & $\begin{array}{c}\text { Nominal } \\
\text { Capacity } \\
\text { Technology }\end{array}$ & $\begin{array}{c}\text { Measured } \\
\text { Capacity } \\
\text { (Ah, 1C rate) }\end{array}$ & $\begin{array}{c}\text { Capacity After } \\
\text { 3onths on Profile } \\
\text { (Ah, 1C rate) }\end{array}$ & $\begin{array}{c}\text { Percentage of } \\
\text { Initial Capacity } \\
\text { After Cycling } \\
\text { (\%Ah, 1C rate) }\end{array}$ \\
\hline A123/ANR26650M1A & 2.30 & 2.21 & 1.91 & $86^{\mathrm{a}}$ \\
Sony/US26650FT & 2.98 & 2.96 & 2.61 & $88^{\mathrm{a}}$ \\
Panasonic/NCR18650 & 2.75 & 2.84 & 2.04 & $72^{\mathrm{b}}$ \\
\hline
\end{tabular}

${ }^{\mathrm{a}}$ After 90 days of duty

${ }^{\mathrm{b}}$ After 19 days of duty

\subsubsection{Metric Four - Operating Efficiency}

The operating efficiency of a technology is important, because it defines the amount of energy available during discharge and the cost to recharge.

Representations of the charging efficiency for the three battery technologies were obtained by plotting Wh versus Ah for each individual charge and discharge step completed during operation under the 20-kWh BES profile, respectively (Figure 16). Once again, the charge efficiency of both the A123/ANR26650MIA and Sony/US26650FT battery technologies are closely matched, whereas the Panasonic/NCR18650 battery technology required considerably more energy to return an equivalent number of Ahs. 


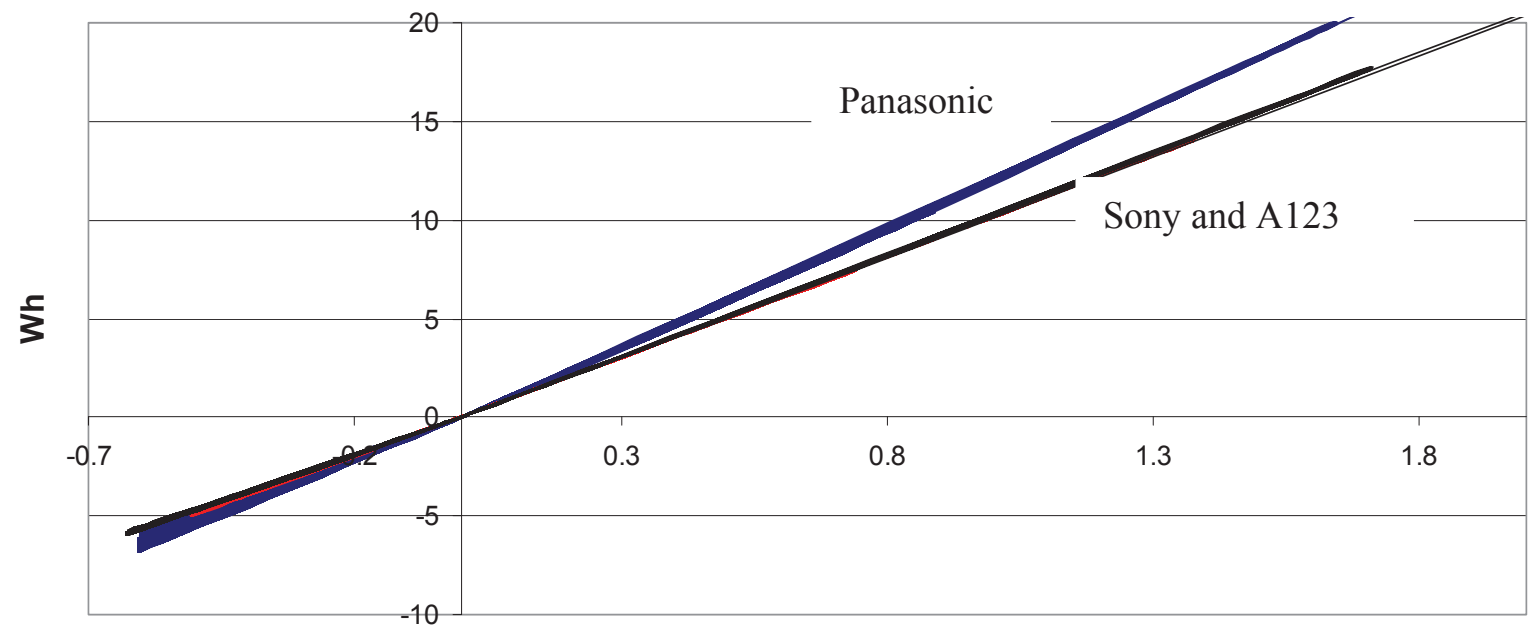

Ah

Figure 16. Wh versus the Ah for the three battery technologies during operation under the 20 -kWh battery energy storage system.

\subsection{Task 3.14.6: Develop and Validate a Test Profile for Evaluating Battery Performance in a 200-kWh Battery Energy Storage System}

\subsubsection{Test Profile for Evaluating Battery Performance in a 200-kWh Battery Energy Storage System}

A profile that simulated operation of a $200-\mathrm{kWh}$ battery in a BES system was developed and termed the 200-kWh BES profile. All power (i.e., $50 \mathrm{~kW}$ ) required for the vehicle charge was provided by this BES system, because it was assumed that no grid power would be available during the daytime. Consequently, the 200-kWh BES system was only recharged at night with off-peak electricity (i.e., no opportunity-charging during the day). However, it could charge vehicles continuously, one at a time, during the daytime. By contrast, vehicles being charged by a 20-kWh BES system may need to wait for the BES system itself to be recharged. Also, the rate of discharge, in comparison to battery capacity, required from the 200-kWh BES system for charging vehicles is one tenth of that experienced by the $20-\mathrm{kWh}$ BES system. Therefore, the operating temperature of the larger system will always be close to ambient. The major disadvantage of the 200-kWh BES system is that its initial capital cost will be much higher than that of the 20-kWh BES system.

The simulated 200-kWh BES profile employs the same discharge pattern as the 20-kWh BES profile; one vehicle charge from 30 to $90 \%$ SOC (requiring $14.4 \mathrm{kWh}$ from the BES system) followed by four vehicle charges from 30 to $60 \%$ SOC (each requiring $7.2 \mathrm{kWh}$ from the BES system) and is continued until the SOC for the BES system drops below 35\%. The profile is summarized in Table 6.

\subsubsection{Validation for the 200-kWh Battery Energy Storage Profile}

Three A123/ANR26650MIA cells, in series, were operated under the 200-kWh BES system in order to validate the procedure, with specific charge and discharge currents applied in order to simulate duty in a full-sized pack. Because the operating conditions of the battery are far less rigorous with this system than with the 20-kW BES system, only one cell type was tested to provide baseline data for and validation of the procedure. The voltage response of the string during operation is shown in Figures 17 and 18, and it should be noted that the charge pattern began its fourth repeat before the EODV limit was reached 
(i.e., 9.6 volts at approximately $35 \%$ SOC; Figure 17). This means that when the BES system is new, it is capable of recharging 15 vehicles during the day before it requires a full charge itself (which occurred only once a day, at night time, with off-peak electricity).

Table 6. State of charge for the 200-kWh battery energy storage system during one duty day.

\begin{tabular}{|c|c|c|}
\hline $\begin{array}{c}\text { Vehicle Charge } \\
(\%)\end{array}$ & $\begin{array}{c}\text { BES System SOC Start } \\
(\%)\end{array}$ & $\begin{array}{c}\text { BES System SOC End } \\
(\%)\end{array}$ \\
\hline 30 to 90 & 95 & 87.8 \\
\hline 30 to 60 & 87.8 & 84.2 \\
\hline 30 to 60 & 84.2 & 80.6 \\
\hline 30 to 60 & 80.6 & 77.4 \\
\hline 30 to 60 & 77.4 & 73.8 \\
\hline 30 to 90 & 73.8 & 66.6 \\
\hline 30 to 60 & 66.6 & 63 \\
\hline 30 to 60 & 63 & 59.8 \\
\hline 30 to 60 & 59.8 & 56.6 \\
\hline 30 to 60 & 56.6 & 53.5 \\
\hline 30 to 90 & 53.4 & 46.2 \\
\hline 30 to 60 & 46.2 & 43 \\
\hline 30 to 60 & 43 & 39.8 \\
\hline 30 to 60 & 39.8 & 36.6 \\
\hline 30 to 60 & 36.6 & 33.4 \\
\hline Off $p$ peak charge & 33.4 & 95 \\
\hline
\end{tabular}

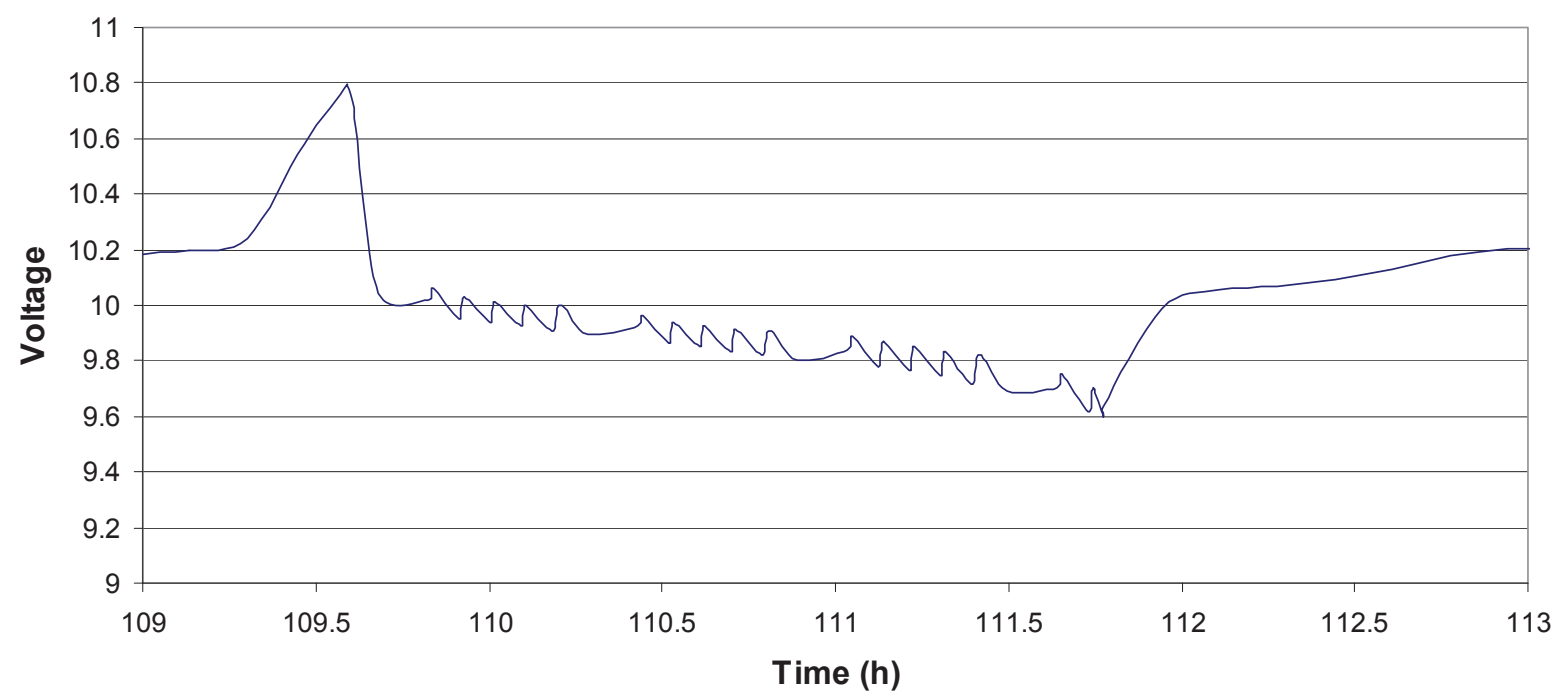

Figure 17. Voltage of A123/ANR26650M1A battery technology operating under the 200-kWh battery energy storage profile (one day of simulated operation). 


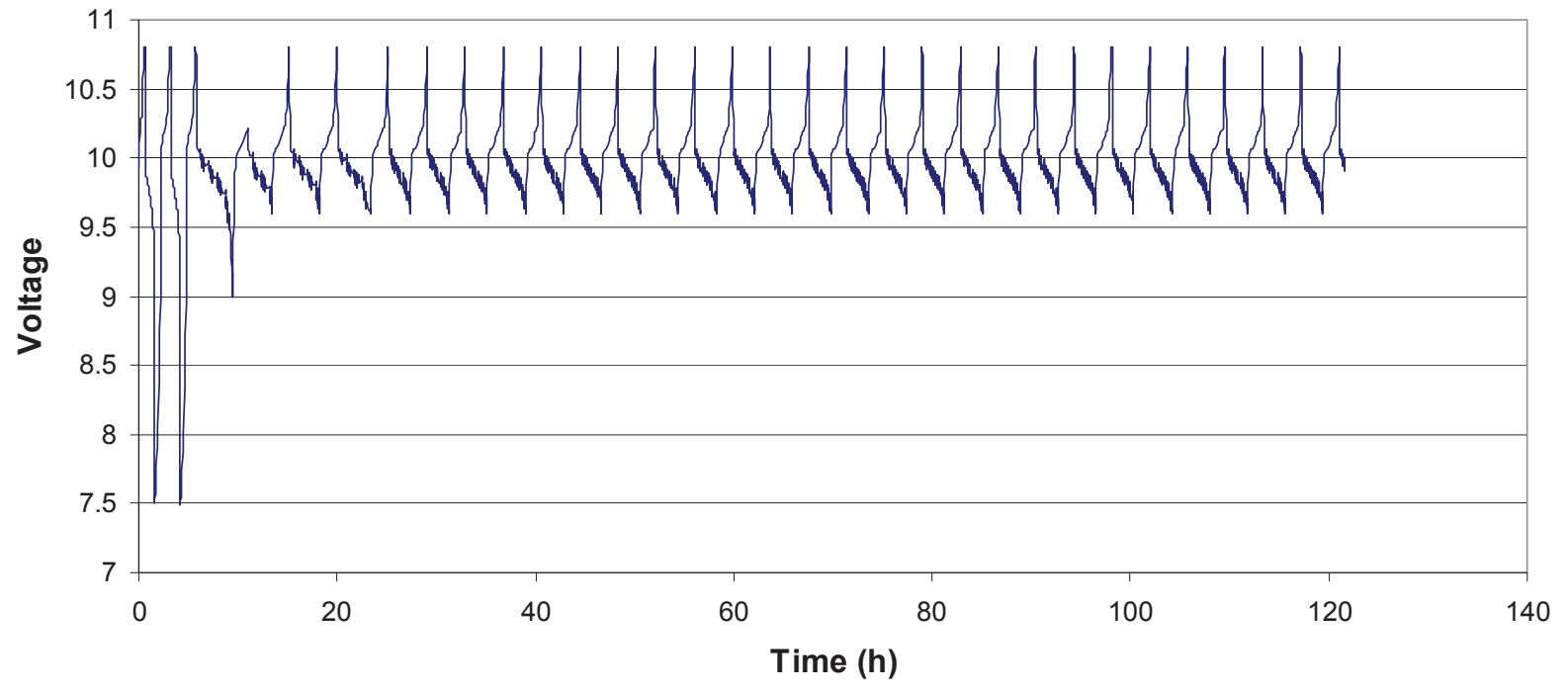

Figure 18. Voltage of A123/ANR26650M1A battery technology operating under the 200-kWh battery energy storage profile.

\section{SUMMARY}

In this project, two laboratory simulation profiles were developed to evaluate battery performance under two different BES systems for demand reduction on DCFC units.

The first simulated BES profile was based on the assumption that battery storage only had a capacity of $20 \mathrm{kWh}$. The power required for the vehicle recharge was co-supplied by the grid $(20 \mathrm{~kW}$ maximum to avoid the demand charge) and the ground storage battery $(30 \mathrm{~kW})$. The BES system had the chance to be recharged by the grid at $20 \mathrm{~kW}$ when a vehicle was not charging.

The second simulated BES profile was based on the assumption that battery storage would be the sole power supply for the vehicle charge. The grid power was not available during the day. The ground storage battery itself could only be recharged during the night, when off-peak electricity was available. Therefore, the second BES system had a much larger capacity at $200 \mathrm{kWh}$.

Both test profiles were validated. Performance metrics, which include battery temperature, battery voltage (especially TOCV and EODV trend), battery capacity, and operating efficiency, were developed to assist the performance comparisons among the different battery technologies. Three different lithium battery technologies, Sony/US26650FT, Panasonic/NCR18650 and A123/ANR26650M1A, were operated under the simulated 20-kWh BES profile for 3 months. The Panasonic/NCR18650 technology failed after 19 days, whereas the Sony/US26650FT and the A123/ANR26650M1A technologies were at $88 \%$ and $86 \%$ of their initial capacities, respectively, at the end of the 3-month test. The relatively higher operating temperatures, voltage drop, and internal resistance of the Panasonic/NCR18650 battery technology suggested that it is not as well suited for the high-rate BES system compared to the evaluated Sony/US26650FT and A123/ANR26650MIA battery technologies. 


\section{APPENDIX}

The test specification for DCFC battery testing referenced in this document is attached as the following pages of this appendix. 


\section{QCOtality}

\section{Test Specification - DCFC Battery Testing}

ECOtality North America 430 S. $2^{\text {nd }}$ Avenue

Phoenix, Arizona 85003-2418

Phone: (602) 716-9576

Fax: (602) 443-9007

www.ecotalityna.com

Submitted by: Jeffrey Wishart, Ph.D. Tyler Gray Jeremy Diez Sally Sun, Ph.D.

Submitted on: 
(C2012 by Electric Transportation Engineering Corporation. All rights reserved.

No part of the contents of this document may be reproduced or transmitted in any form or by any means without the express written permission of Electric Transportation Engineering Corporation, dba ECOtality North America ${ }^{\mathrm{TM}}$.

\section{Document Information}

\begin{tabular}{|l|l|l|}
\hline Rev \# & Changes Made & \\
\hline & & \\
\hline & & \\
\hline
\end{tabular}

\section{ecotality}

NORTH AMERICA

Electric Transportation Engineering Corporation dba ECOtality North America 430 S. $2^{\text {nd }}$ Avenue Phoenix, Arizona 85003-2418 (602) 716-9576

www.ecotalityna.com 


\section{Table of Contents}

1 Objective ..................................................................................... 1

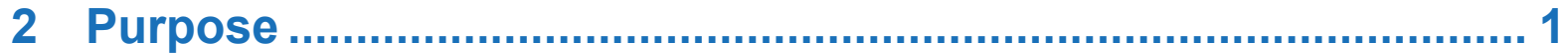

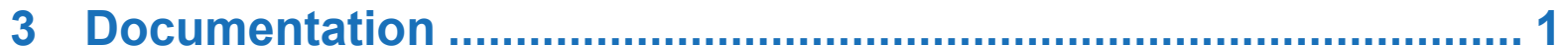

4 Initial Conditions \& Prerequisites ............................................... 1

5 Charging Requirements ........................................................... 4

6 Glossary ........................................................................................... 7

7 References .......................................... Error! Bookmark not defined. 


\section{Objective}

This objective of this Test Specification is to provide a method for testing the DC Level 2 (aka DCFC) charging of the main propulsion energy storage system (ESS) of capable vehicles participating in advanced vehicle testing.

\section{Purpose}

The purpose of this Test Specification is to identify testing methodology for vehicles with DC Level 2 charging capable energy storage systems. This Test Specification outlines the methods for experimental conduct.

\section{Documentation}

Documentation addressed by this Test Specification shall be consistent, easy to understand, easy to read and readily reproducible. Review and approval of test documentation shall be in accordance with appropriate quality control procedures. Storage and retention of records during and following testing activities shall be completed in accordance with appropriate document control procedures. 


\section{Initial Conditions \& Prerequisites}

Prior to conduct of any portion of the testing, the following initial conditions and prerequisites shall be met.

\subsection{Personnel}

Personnel conducting testing under this Test Specification, i.e., the Test Engineer, shall be familiar with the requirements of this Test Specification, shall be trained in accordance with the requirements, and be certified by the Test Manager prior to commencing any testing activities.

\subsection{Vehicle Modes}

In order to test the amount of energy that the DC Level 2 charge event provides to the vehicle, all vehicles shall be tested with the ESS state-of-charge (SOC) or allelectric calculated range at the lowest possible value while still assuring driver safety. The manufacturer's user manual should be consulted to provide safe operating practices. Some vehicles may have a 'limp home mode' that prevents the vehicle from operating normally when it has reached the low end of the ESS operating capability. If such a mode exists for a particular vehicle, entering it while driving should be considered to be a sufficient ESS depletion criterion for this testing.

NOTE: No particular route need be utilized to get the vehicle into the proper testing mode.

\subsection{Vehicle Conditions}

4.3.1 Vehicles to be tested should have an appropriate charging port/connection capable of handling the voltage and current required to charge the ESS in one hour or less.

4.3.2 Vehicles should utilize a standardized DC Level 2 charging protocol interface, such as the CHAdeMO ${ }^{\text {TM }}$ standard or one defined by the SAE. If no standardized protocol is present, the vehicle manufacturer must provide or approve a charger that can fully recharge the main propulsion ESS from any state of discharge in less than one hour and should have the ESS manufacturer review and approve the charging algorithm.

\subsection{Environmental Conditions}

All charging will take place in a temperature controlled chamber. The ambient temperature during testing shall be set as indicated in Section 5 of this document, and shall not deviate more than $5^{\circ} \mathrm{F}\left(3^{\circ} \mathrm{C}\right)$ at any time. 


\subsection{Instrumentation}

4.5.1 All instrumentation used during testing shall be calibrated. The calibration shall be performed and documented to ensure compliance with this requirement. Certainty that all instrumentation used for this testing is calibrated shall be made prior to testing.

4.5.2 All instrumentation shall have the accuracies and resolutions noted. Unless specific exceptions have been made by the Test Manager, the following identifies the minimum instrumentation specification that shall be installed and employed during the testing:

\subsubsection{Temperature}

The temperature indicating devices must have a resolution of $2{ }^{\circ} \mathrm{F}$ $\left(1^{\circ} \mathrm{C}\right)$ and an accuracy of $\pm 2^{\circ} \mathrm{F}\left( \pm 1^{\circ} \mathrm{C}\right)$. The sensing element shall be shielded from radiant heat sources.

\subsubsection{ESS Charging Current}

Accuracy requirement is $\pm 1 \mathrm{~A}$

\subsubsection{ESS Voltage}

Accuracy requirement is $\pm 1 \mathrm{~V}$

\subsection{Test Conduct}

4.6.1 Any deviation from the test procedure and the reason for the deviation shall be recorded.

4.6.2 All documentation required to complete testing shall be completed, approved and ready for issue prior to commencing the testing it addresses. 


\section{Test Activity Requirements}

This section addresses testing required to meet the stated purpose and objective of this Test Specification.

\subsection{Collected Test Data}

The following data shall be collected during conduct of the test specified by this document.

\subsubsection{ESS temperature}

5.1.2 ESS voltage versus time

5.1.3 ESS current versus time

5.1.4 Charge energy

5.1.5 Vehicle Energy Indicator (VEI) data

\subsection{Collected Environmental Conditions Data}

Charging is to be conducted in a temperature controlled testing chamber. This chamber shall be capable of averaging an ambient temperature range of $32^{\circ} \mathrm{F}(0$ $\left.{ }^{\circ} \mathrm{C}\right)$ to $125^{\circ} \mathrm{F}\left(50^{\circ} \mathrm{C}\right)$.

\subsection{Test Requirements}

The purpose of this section is to gather information regarding the DC Level 2 charging capabilities of all vehicles designed by their manufacturers for such charging. This testing is to be completed subject to the initial conditions and prerequisites stated in Section 4 of this document.

CAUTION: All personnel who will conduct charging operations shall be specifically trained in all aspects of the charger, including its automatic shutdowns and safety procedures.

5.3.1 All charges will span from the lowest to the highest vehicle energy indicator value (SOC, calculated range, etc.) allowed within the safe operating practices of the vehicle.

5.3.2 Tests will be conducted at ambient temperatures of $32^{\circ} \mathrm{F}\left(0^{\circ} \mathrm{C}\right), 77^{\circ} \mathrm{F}(25$ $\left.{ }^{\circ} \mathrm{C}\right)$ and $122^{\circ} \mathrm{F}\left(50^{\circ} \mathrm{C}\right)$.

5.3.3 Vehicles to be tested will be temperature soaked in the testing chamber for 12 hours prior to undergoing charging.

5.3.4 Vehicles should stay within 10 miles of the testing chamber location while ESS is being depleted.

5.3.5 When the vehicle indicates 15 miles of range remaining, or the equivalent, the test driver shall return to the testing chamber facility. If upon arriving at 
the facility the energy indicator is not at the desired value then the vehicles accessory loads will we turned on to full power in an attempt to reach the desired value. If the accessory loads do not receive energy from the traction ESS, then the vehicle shall be driven but will not exceed a distance of two miles from the testing facility.

5.3.6 A charge is considered complete when the charger stops delivering current to the vehicle ESS.

5.3.7 Record the following information as appropriate when the charge begins and has completed.

\subsubsection{Time}

5.3.7.2 Charging station energy meter (if available)

5.3.7.3 Vehicle SOC (if available)

5.3.7.4 Vehicle calculated range (if available)

\subsection{Charging Performance Metrics}

5.4.1 ESS temperature difference over the duration of testing.

$$
\Delta T=T_{F}-T_{I}
$$

5.4.2 Vehicle Energy Indicator Return Rate, represented by the VEI, over the charge time. The VEI can be provided in units of SOC or, more likely, miles. The VEI Return rate is therefore a metric in $\triangle \mathrm{SOC} / \mathrm{min}$ or miles/min.

$$
\text { Vehicle Energy Indicator Return Rate }=\frac{\left(V E I_{F}-V E I_{I}\right)}{\text { Charge Time }}
$$

5.4.3 Actual energy returned to the vehicle ESS over the charge time.

$$
\text { Energy Return Rate }=\frac{\text { Charge Energy }}{\text { Charge Time }}
$$

\subsection{Charging Efficiencies}

This section provides guidance on calculating charging efficiencies. Charging efficiencies should be calculated using the Testing Charging Efficiency equation shown in this section and either a constant speed range test performed on a closed track or a designated highway route that best emulates a closed track.

5.5.1 Calculating Charging Efficiency with range testing data

Testing Charging Efficiency $=\frac{\text { Energy output during range testing }}{\text { Energy input during DC L2 Charging }}$

5.5.2 Charging Efficiency with Designated Highway Route

In the event that DC Level 2 charging does not allow for a $\pm 3 \%$ SOC matching to that of the starting SOC of any previously performed range testing, a designated route combining city and highway driving should be 
used after DC Level 2 charging to collect vehicle output energy. The route should be mostly highway driving and the driver should attempt, as best possible, to maintain a single speed used during Range Testing that conforms to posted speed limits. A route shall be considered complete when the vehicle SOC or, if unavailable, the calculated range is the same as the recorded value prior to DC Level 2 charging. 
Charge-Depleting (CD) Mode: An operating mode in which the energy storage system (ESS) state of charge (SOC) is depleted (not continuously, but the trend is depletion) while the vehicle is driven. May be ESS-Only (i.e., the vehicle operates solely on energy from the ESS) or Blended CD (i.e., the vehicle operates on energy from both the ESS and the consumable fuel energy converter (CFEC)).

Charge-Sustaining (CS) Mode: An operating mode in which the energy storage system (ESS) state of charge (SOC) is maintained within a prescribed range by operation of a consumable fuel energy converter (CFEC).

Consumable Fuel Energy Converter (CFEC): An engine which consumes fuel to produce work (either electrical or mechanical).

Curb Weight: The total weight of the vehicle including batteries, lubricants, and other expendable supplies but excluding the driver, passengers, and other payloads.

Effective Date: After a Checklist, Test Specification, or Work Instruction has been reviewed and approved, the first date the procedure can be utilized official data collection and testing.

Energy Storage System (ESS): A component or system of components that stores energy and for which its supply of energy is rechargeable by an electric motor-generator system, an off-vehicle energy source, or both. Examples of ESSs include batteries, capacitors, and electromechanical flywheels.

ESS-Only Mode (ESS Only): An operator selectable vehicle operating mode in which the CEFC is disabled and the vehicle operates solely on energy from the ESS.

Gradeability: The maximum percent grade which the vehicle can traverse for a specified time at a specified speed. The gradeability limit is the grade upon which the vehicle can just move forward.

Initial Conditions: Conditions that must exist prior to an event occurring.

Initial State of Charge (SOC): ESS SOC at the beginning of a test.

Prerequisites: Requirements that shall be met or resolved prior to an event occurring.

SAE: Society of Automotive Engineers

Shall: This word is used to indicate an item which requires adherence without deviation. 'Shall' is used to identify the binding requirements in a statement. A go or no-go criterion.

Should: This word is used to identify an item, which requires adherence if at all possible. 'Should' statements identify preferred conditions.

State of Charge (SOC): The ESS SOC is defined as the present capacity, (ampereshours or watt-hours or miles), expressed as a percentage of the total available. 
Test Engineer: The individual(s) assigned responsibility for the conduct of any given test.

Test Manager: The individual responsible for the implementation of the test program for any given vehicle undergoing advanced vehicle testing at ECOtality North America.

Test Mass (Weight): The mass [weight] of the vehicle as tested; including driver and all instrumentation.

Tractive Force: The force available from the driving wheels at the driving wheel/ground interface. 